\title{
A New Italian Purple Corn Variety (Moradyn) Byproduct Extract: Antiglycative and Hypoglycemic In Vitro Activities and Preliminary Bioaccessibility Studies
}

\author{
Lucia Ferron ${ }^{1,2}$, Raffaella Colombo ${ }^{1}\left[\right.$, Barbara Mannucci ${ }^{3}\left(\mathbb{D}\right.$ and Adele Papetti ${ }^{1, *(1)}$ \\ 1 Department of Drug Sciences, University of Pavia, Viale Taramelli 12, 27100 Pavia, Italy; \\ lucia.ferron01@universitadipavia.it (L.F.); raffaella.colombo@unipv.it (R.C.) \\ 2 FlaNat Research Italia Srl, Via Giuseppe di Vittorio 1, 20017 Rho (Milano), Italy \\ 3 Centro Grandi Strumenti, University of Pavia, Via Bassi 21, 27100 Pavia, Italy; barbara.mannucci@unipv.it \\ * Correspondence: adele.papetti@unipv.it; Tel.: +39-0382-9878-63; Fax: +39-0382-4229-75
}

Academic Editor: Teresa Escribano-Bailón

Received: 19 March 2020; Accepted: 20 April 2020; Published: 23 April 2020

\begin{abstract}
The reuse of byproducts from agricultural and food industries represents the key factor in a circular economy, whose interest has grown in the last two decades. Thus, the extraction of bioactives from agro-industrial byproducts is a potential source of valuable molecules. The aim of this work was to investigate the in vitro capacity of byproducts from a new Italian corn variety, named Moradyn, to inhibit the accumulation of advanced glycation end products (AGEs) involved in several chronic age-related disorders. In addition, the hypoglycemic effect of Moradyn was tested by in vitro enzymatic systems. A Moradyn phytocomplex and its purified anthocyanin fraction were able to inhibit fructosamine formation and exhibited antiglycative properties when tested using BSA-sugars and BSA-methylglyoxal assays. These properties could be attributed to the polyphenols, mainly anthocyanins and flavonols, detected by RP-HPLC-DAD-ESI-MS ${ }^{n}$. Finally, a Moradyn phytocomplex was submitted to a simulated in vitro digestion process to study its bioaccessibility. Moradyn could be considered as a promising food ingredient in the context of typical type 2 diabetes risk factors and the study will continue in the optimization of the ideal formulation to preserve its bioactivities from digestion.
\end{abstract}

Keywords: Zea mays L.; purple corn byproduct; circular economy; polyphenols; anthocyanins; antiglycative capacity; advanced glycation end products; hypoglycemic effect; in vitro simulated digestion process

\section{Introduction}

Nowadays, the interest towards purple corn and its phytocomplex composition is rapidly growing. Pigmented maize varieties are typical Peruvian and Bolivian crops, used to prepare local drinks and desserts, whose bright color is due to the presence of high anthocyanin levels in their phytocomplex [1]. All maize varieties generally possess genes correlated to pigment synthesis, but Southern American environmental factors such as temperature, light exposure, and UV radiation elicit biosynthetic pathways leading to anthocyanin accumulation [2].

In the literature, research investigating the composition of purple corn extracts obtained from different tissues, i.e., kernel, cob, husk, and silk, has been reported [1-6]. All extracts share a common basic composition consisting of six main anthocyanins: Cyanidin-3-O-glucoside, perlagonidin-3-Oglucoside, peonidin 3-O-glucoside, and their malonylated forms $[1,5,7,8]$. Besides these major compounds, other derivatives have been detected: Catechin-(4,8)-pelargonidin-3,5-di-O-glucoside,afzelechin-(4,8)- 
pelargonidin-3,5-di-O-glucoside [3]; cyanidin-, peonidin-, and perlargonidin-3-O-di-malonylglucoside [9], cyanidin-3-O-succinylglucoside, cyanidin-3-O-malonylglucoside-5-O-glucoside [5], and cyanidin-3,5di-O-glucoside, this one identified for the first time in purple corn by Žilić et al. [10]. Moreover, several authors have detected ethyl-malonylated anthocyanins that probably originate during the extraction process, and which are known to stabilize pigments, thus prolonging shelf life $[5,8]$.

Husk and cob extracts are richer in anthocyanins than kernel extracts, ranging from $0.49 \%$ to $4.6 \%$ (dry weight) for cobs [1,5]; moreover, husks and cobs differ from kernels for the presence of perlagonidin in their phytocomplex [3].

Nowadays, several food byproducts such as olive leaves and oil mill wastewater, grape skin, fruit and vegetable seeds, and artichoke bracts and stems have been deeply investigated for their important role in the inhibition of advanced glycation end products (AGEs) formation [11-15]. AGEs are typical adducts derived from Maillard reaction or non-enzymatic glycation process. These compounds are involved in many chronic diseases, such as cardiovascular pathologies, type 2 diabetes, and neurodegenerative disorders, and their formation increases in association with hyperglycemia and metabolic dysfunctions [16-19]. Thanks to their high polyphenol content, purple corn byproducts have been associated with several health properties such as antioxidant, anti-inflammatory, and antiglycative activity $[2,10,20-23]$. Moreover, in vitro and in vivo studies demonstrate their capacity in the prevention of cardiovascular and type 2 diabetes risk factors by exerting a strong anti-hypertensive effect, lowering cholesterol level, ameliorating insulin resistance, and improving lipid profile in high-fat diet treated rats [24-28].

However, it is well known that all these health benefits can occur only if the putatively active compounds are bioavailable. Bioavailability is markedly affected by bioaccessibility, i.e., the release of compounds after their intake with food, and by the chemical transformations occurring during gastrointestinal metabolism (digestibility factor) [29,30]; therefore, the evaluation of these two parameters is mandatory in order to adequately investigate the effectiveness of bioactive molecules in vitro [31,32].

Recently, FlaNat Research Italia Srl (Rho, MI, Italy) developed a new Italian purple corn variety, named Moradyn, which is able to sprout and grow in northern Italy, maintaining a highly pigmented cob. Thus, the aim of the present work is to investigate the health properties of Moradyn phytocomplex cob extract (CE), compared with its purified anthocyanin fraction (AF). In particular, the capacity to avoid the accumulation of AGEs was evaluated and hypoglycemic effects were assessed by using in vitro assays. Furthermore, phytocomplex composition was completely characterized by LC-MS technique and a preliminary bioaccessibility study was performed by a simulated in vitro static digestion procedure.

\section{Results and Discussion}

First of all, Moradyn CE was chemically characterized and tested for its antiglycative and hypoglycemic activities, as well as its isolated AF. Then, the phytocomplex was submitted to a simulated in vitro static digestion process for the evaluation of its bioaccessibility.

\subsection{Chemical Characterization of Moradyn Cob Extract by RP-HPLC-DAD-ESI-MS ${ }^{n}$}

The qualitative profile of Moradyn CE was investigated by RP-HPLC-DAD-ESI-MS ${ }^{\mathrm{n}}$ using a data-dependent acquisition mode. Figure 1a,b reports the base peak chromatogram registered in the positive and negative ionization modes, respectively. Twenty compounds were detected and identified by comparing their selectivity, UV-Vis spectra, information on pseudo-molecular ions, and fragmentation patterns with reference to pure standard compounds, where commercially available, or with data reported in the literature. Table 1 summarizes all the compounds identified in Moradyn cob extract by LC-MS ${ }^{\text {. }}$. 
a)

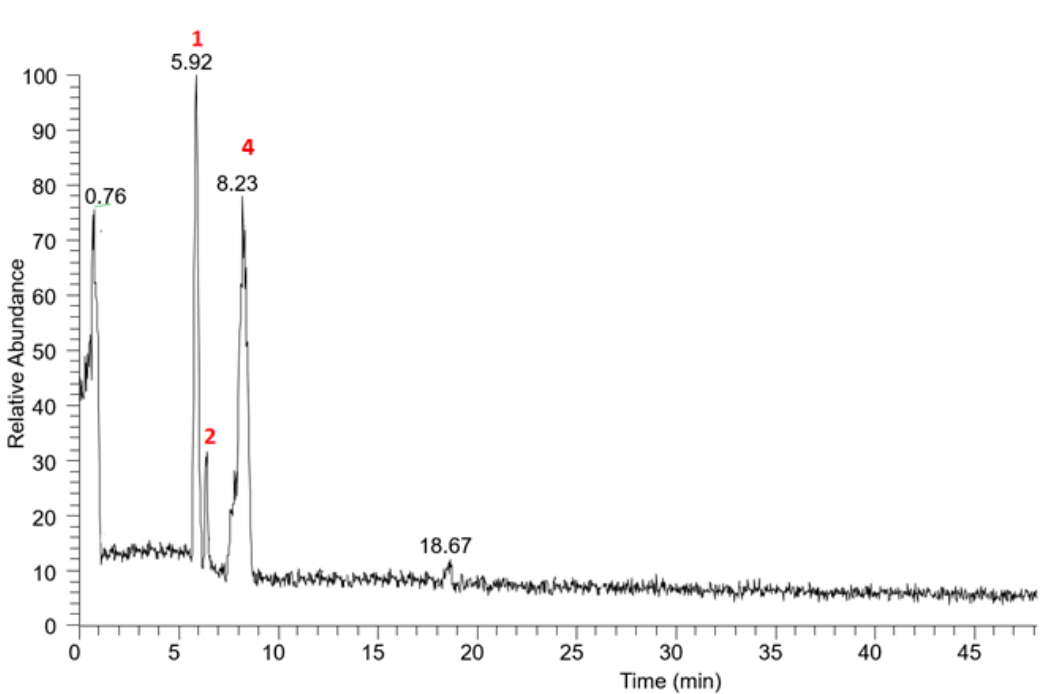

b)

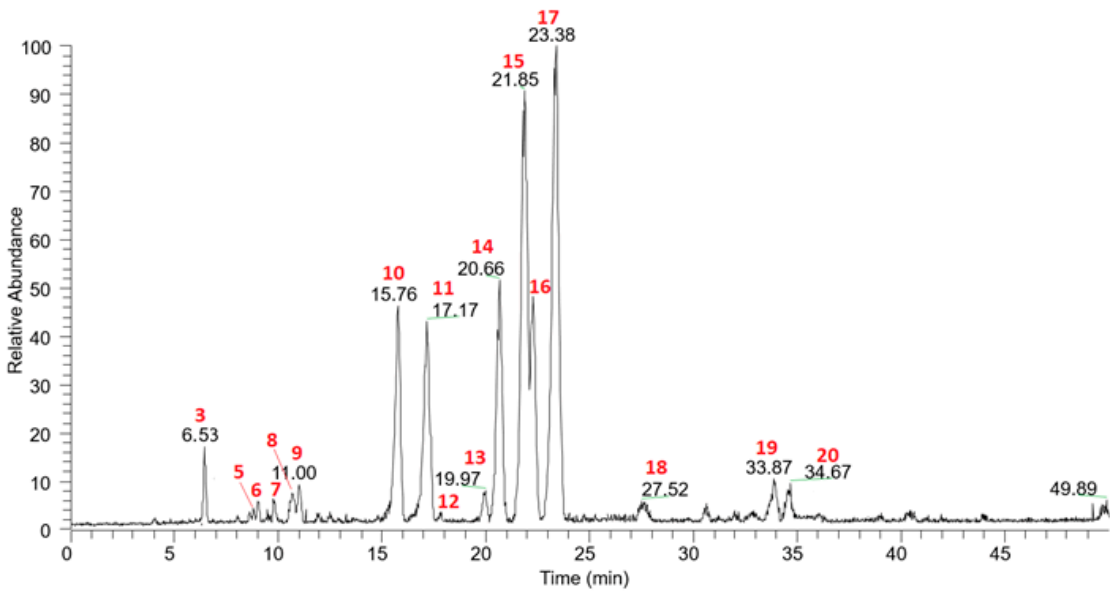

Figure 1. Base peak chromatograms registered in (a) positive and (b) negative ionization mode for Moradyn CE.

Table 1. MS and MS ${ }^{n}$ data (negative or positive ionization modes) of the compounds identified in Moradyn cob extract (CE). Compounds are reported in order of elution; * positive ionization mode; a compared with standard compounds.

\begin{tabular}{|c|c|c|c|c|}
\hline Compound & Rt (min) & $\begin{array}{l}\text { Precursor Ion } \\
(\mathrm{m} / \mathrm{z})\end{array}$ & $\begin{array}{c}\text { HPLC-ESI-MS }^{n} \\
m / z \text { (\% of Base Peak) }\end{array}$ & Compound Identity \\
\hline $1^{\mathrm{a}}$ & 5.92 & $449 *$ & MS2[449]: 287(100) & cyanidin-3-O-glucoside \\
\hline $2^{a}$ & 6.41 & $433 *$ & MS2[433]: 271(100) & pelargonidin-3-O-glucoside \\
\hline $3^{\text {a }}$ & 6.53 & 431 & MS2[431]: 269 (100), 268 (85) & apigenin-7-O-glucoside \\
\hline $4^{\mathrm{a}}$ & 8.23 & $463 *$ & MS2[463]: 301(100) & peonidin-3-O-glucoside \\
\hline 5 & 8.49 & 641 & $\begin{array}{l}\text { MS2[641]: 479(100), 317(27) } \\
\text { MS3[479]: 317(100) }\end{array}$ & myricetin-3,7-di-O-hexoside \\
\hline 6 & 8.70 & 459 & MS2[459]: 235(30), 193(100), 149(30) & ferulic acid derivative \\
\hline 7 & 9.77 & 479 & MS2[479]: 317(100), 316(5), 299(70) & myricetin-7-O-hexoside \\
\hline 8 & 10.67 & 367 & $\begin{array}{l}\text { MS2[367]: 191(100), 173(20) } \\
\text { MS3[191]: 172(40), 127(80), 85(100) }\end{array}$ & 5-O-feruloylquinic acid \\
\hline 9 & 11.00 & 639 & $\begin{array}{l}\text { MS2[639]: 477(100), 315(5) } \\
\text { MS3[477]: 315(100), 300(10) }\end{array}$ & isorhamnetin-3,7-di-O-hexoside \\
\hline 10 & 15.76 & 609 & MS2[609]: 463(5), 301(100), 300(50) & quercetin-7-O-p-cumaroylhexoside \\
\hline $11^{\mathrm{a}}$ & 17.17 & 463 & MS2[463]: $301(100), 300(30)$ & quercetin-7-O-glucoside \\
\hline 12 & 17.97 & 609 & MS2[609]: 447(100), 285(30) & keampferol-3,7-di-O-hexoside \\
\hline
\end{tabular}


Table 1. Cont.

\begin{tabular}{|c|c|c|c|c|}
\hline Compound & Rt (min) & $\begin{array}{c}\text { Precursor Ion } \\
(\mathrm{m} / \mathrm{z})\end{array}$ & $\begin{array}{c}\text { HPLC-ESI-MS }^{n} \\
m / z \text { (\% of Base Peak) }\end{array}$ & Compound Identity \\
\hline 13 & 19.97 & 533 & $\begin{array}{c}\text { MS2[533]: } 447(26), 285(100), 284(38) \\
\text { MS3[285]: } 267(15), 257(100), 241(25), \\
\text { 199(10), 163(5) } \\
\text { MS2[593]: } 447(70), 285(100), 257(15)\end{array}$ & $\begin{array}{c}\text { keampferol-7- } \\
\text { O-(6"-O-malonyl)-hexoside }\end{array}$ \\
\hline 14 & 20.66 & 593 & $\begin{array}{c}\text { MS3[285]: } 267(15), 257(100), 241(10), \\
199(20)\end{array}$ & keampferol-7-O-rutinoside \\
\hline 15 & 21.85 & 623 & $\begin{array}{c}\text { MS2[623]: 477(20), 315(100) } \\
\text { MS3[315]: 300(100) }\end{array}$ & isorhamnetin-7-O-rutinoside \\
\hline 16 & 22.24 & 447 & $\begin{array}{c}\text { MS2[447]: } 327(20), 285(100), 284(85), \\
257(30), 255(5)\end{array}$ & kaempferol-7-O-glucoside \\
\hline 17 & 23.26 & 477 & $\begin{array}{c}\text { MS2[477]: 315(35), 314(100) } \\
\text { MS3[315]: 300(100) }\end{array}$ & isorhamnetin-3-O-hexoside \\
\hline $18^{\mathrm{a}}$ & 27.52 & 447 & $\begin{array}{c}\text { MS2[447]: 285(100), 284(95), 151(10), } \\
133(6) \\
\text { MS3[285]: 267(40), 257(20), 241(40), } \\
\text { 199(10), 175(100) }\end{array}$ & luteolin-7-O-glucoside \\
\hline 19 & 33.87 & 785 & $\begin{array}{l}\text { MS2[785]: } 609(20), 447(100) \\
\text { MS3[447]: } 285(100), 284(80)\end{array}$ & $\begin{array}{l}\text { kaempferol-3-O-hexosyl-7- } \\
\text { O-glucuronilhexoside }\end{array}$ \\
\hline 20 & 34.67 & 815 & $\begin{array}{l}\text { MS2[815]: } 639(60), 477(100) \\
\text { MS3[477]: } 315(100), 300(10)\end{array}$ & $\begin{array}{l}\text { isorhamentin-3-O-hexosyl-7- } \\
\text { O-glucuronilhexoside }\end{array}$ \\
\hline
\end{tabular}

Three anthocyanins were detected: cyanidin-3-O-glucoside (1) $\left(\mathrm{m} / \mathrm{z} 449\left[\mathrm{M}^{+}\right]\right)$, pelargonidin-3$O$-glucoside (2) $\left(\mathrm{m} / z 433\left[\mathrm{M}^{+}\right]\right)$, and peonidin-3-O-glucoside (4) $\left(\mathrm{m} / \mathrm{z} 463\left[\mathrm{M}^{+}\right]\right)$. All these compounds lost their hexosyl moiety (162 Da), yielding their corresponding aglycons, and their structures were confirmed by comparison with standard pure compounds tested in the same experimental conditions. Their presence has been previously reported in pericarp-pigmented corn lines from the landrace Apache Red [2], in the pericarp of cvs Arrocillo and Peruano, and in the endosperm of cv Purepecha [33]. Moreover, the same compounds have been generally identified in purple corn cob (Zea mays L.), seed (cv Zihei), husk [1,4,8,9,22], and also in the waste derived from a commercial purple corn colorant [6]. Cyanidin-3-O-glucoside was generally the main component, as confirmed by the analysis of purple corn husk deriving from 295 selected lines from the 2006 breeding population [4].

Concerning flavonoids, kaempferol and isorhamnetin derivatives differently glycosylated were the most representative. Considering the loss of $162 \mathrm{amu}$ and the fact that the relative abundance of the radical aglycon ion (deriving from a hemolytic cleavage of deprotonated compound) is higher than the aglycon (deriving from the fragmentation of heterolytic cleavage) [34], compound 17 was identified as isorhamnetin-3-O-hexoside $\left(\mathrm{m} / \mathrm{z} 477[\mathrm{M}-\mathrm{H}]^{-}\right)$. The structure of isorhamentin aglycon was confirmed by the presence of the intense peculiar ion at $\mathrm{m} / \mathrm{z} 300$ in $\mathrm{MS}^{3}$ spectrum, which led us to discriminate the isobaric compounds rhamnetin and isorhamentin [35]. Two isorhamnetin derivatives differently diglycosylated were identified: isorhamnetin-7-O-rutinoside (compound 15) and isorhamnetin 3,7-di-O-hexoside (compound 9). The first one $\left(\mathrm{m} / \mathrm{z} 623[\mathrm{M}-\mathrm{H}]^{-}\right)$fragmented producing the $\mathrm{MS}^{2}$ base peak at $m / z 315[\mathrm{M}-308]^{-}$and a less intense peak ion at $m / z 477[\mathrm{M}-146]^{-}$according to the fragmentation of a disaccharide residue with a $1 \rightarrow 2$ linkage between the monosaccharides [36]. The second one $\left(\mathrm{m} / \mathrm{z} 639[\mathrm{M}-\mathrm{H}]^{-}\right)$fragmented showing the sequential loss of two hexose moiety and was detected as isorhmanetin-3,7-di-O-glucoside. Finally, the last isorhamnetin derivative detected was compound 20; it was putatively identified as isorhamentin-3-O-hexosyl-7-O-glucuronilhexoside by the loss of a glucuronilhexosyl moiety $(338 \mathrm{amu})$ followed by the subsequent loss of another hexoside. The same fragmentation pattern was registered for a kaempferol derivative, indicating keampferol-3-O-hexosyl-7-O-glucuronilhexoside as the putative chemical structure (compound 19, $\left.\mathrm{m} / \mathrm{z} 785[\mathrm{M}-\mathrm{H}]^{-}\right)$. Using the same approach characterized by the loss of sugar moieties, kaempferol-7-O-rutinoside (compound 14, $\mathrm{m} / \mathrm{z} 593[\mathrm{M}-\mathrm{H}]^{-}$), keampferol-7-O-glucoside (compound 16, $\left.\mathrm{m} / \mathrm{z} 447[\mathrm{M}-\mathrm{H}]^{-}\right)$, kaempferol-7-O-(6"-O-malonyl)-hexoside (compound 13, m/z $533[\mathrm{M}-\mathrm{H}]^{-}$), and kaempferol-3,7-di-O-hexoside (compound 12, m/z $609[\mathrm{M}-\mathrm{H}]^{-}$) were detected. Considering a 
parent ion with $m / z$ 609, another isobaric compound was found in Moradyn extract (compound 10); its fragmentation gave a base peak at $m / z 301[\mathrm{M}-\mathrm{H}-308]^{-}$, and secondary peaks at $m / z 300$ (relative intensity 50\%) and $m / z 463$ (relative intensity 5\%), respectively. This fragmentation pattern could putatively be attributed to the presence of quercetin-7-O-rutinoside or more probably to quercetin-7-O- $p$-coumaroylhexoside, considering the very low abundance of $m / z 463$. Moreover, quercetin-7-O-glucoside (compound 11, $\mathrm{m} / \mathrm{z} 463[\mathrm{M}-\mathrm{H}]^{-}$) was also identified and its chemical structure was confirmed by the analysis of the pure standard compound. Finally, myricetin-7-O-hexoside (compound 7, m/z $479[\mathrm{M}-\mathrm{H}]^{-}$) and myricetin-3,7-di-O-hexoside (compound 5, m/z $641[\mathrm{M}-\mathrm{H}]^{-}$) were detected, together with another compound with molecular mass $448 \mathrm{Da}$ (compound 18) whose $\mathrm{MS}^{2}$ spectrum gave as base peak an ion at $m / z 285$ and as secondary peaks the key aglycon fragments at $m / z 241$ and 175 [37]. The compound was identified as luteolin-7-O-glucoside (a flavone derivative) by comparing its fragmentation pattern with that of the reference standard compound. Another flavone derivative was present: compound $3\left(\mathrm{~m} / z 431[\mathrm{M}-\mathrm{H}]^{-}\right)$, that fragmented to yield $\mathrm{m} / z 269$ as the base peak ion and $m / z 268$ as the radical aglycon ion, thus leading to the identification of apigenin-7-O-glucoside; the analysis of the reference compound confirmed the chemical structure.

The last two compounds detected in the extract were hydroxycinnamic acid derivatives: compound $8\left(\mathrm{~m} / z 367[\mathrm{M}-\mathrm{H}]^{-}\right)$showed the typical pattern of 5-O-feruloylquinic acid [38], while compound 6 $\left(\mathrm{m} / z 459[\mathrm{M}-\mathrm{H}]^{-}\right)$was a feruloyl derivative. Ferulic acid and its derivatives were previously detected in purple corn flour [39], in colored kernels from ten different genotypes [9], and in a particular Peruvian purple accession [40].

Anyway, even if the tested Moradyn phytocomplex derived from the morado variety, it is quite different from the other Peruvian varieties. In fact, no malonylated anthocyanins were detected; conversely, it is rich in flavonols such as quercetin, myricetin, isorhamnetin, and kaempferol derivatives. These differences are probably related not only to its genotype but also to environmental factors such as the photoperiod $[1,8,21,39,40]$.

\subsection{Evaluation of Hypoglycemic Activity}

Hypoglycemic activity of $\mathrm{CE}$ and AF was tested by evaluating their inhibitory activity against $\alpha$-glucosidase and $\alpha$-amylase, two of the main enzymes involved in postprandial hyperglycemia modulation [41]. AF represents $28 \%$ (g/g dry CE) and this recovery agreed with the range of data reported in literature by Lee et al. [5] and Lao et al. [1] for other purple corn cob varieties. CE showed a strong dose-dependent inhibitory activity on $\alpha$-glucosidase (Figure 2) which was completely inhibited in presence of $1 \mathrm{mg} / \mathrm{mL} \mathrm{CE}$, differently from acarbose (used as positive control) that inhibited only about $78 \%$ of the enzyme activity when tested at the same concentration. Regarding the isolated AF, it completely inhibited the enzyme activity when tested at $0.5 \mathrm{mg} / \mathrm{mL}$. Conversely, neither CE nor AF were active against $\alpha$-amylase at the same concentrations tested in the previous assay. The results here obtained are in agreement with those reported by Flores et al. [42] and Di Sotto et al. [43], indicating low inhibitory activity against $\alpha$-amylase for extracts free of ellagitannins, syringic acid or rutin; moreover, flavonoids have a different effect on such enzymes depending on their conjugation site and class of the sugar moiety [44]. Even if cyanidin-3-O-glucoside, known to be a potent inhibitor [45], is the main anthocyanin present in $\mathrm{CE}$, the simultaneous presence of many different polyphenols overall may lead to the loss of activity. Therefore, these results suggest that Moradyn hypoglycemic activity could be probably due to a strong synergistic action exerted by all the compounds present in the phytocomplex, and not only to the anthocyanin fraction. 


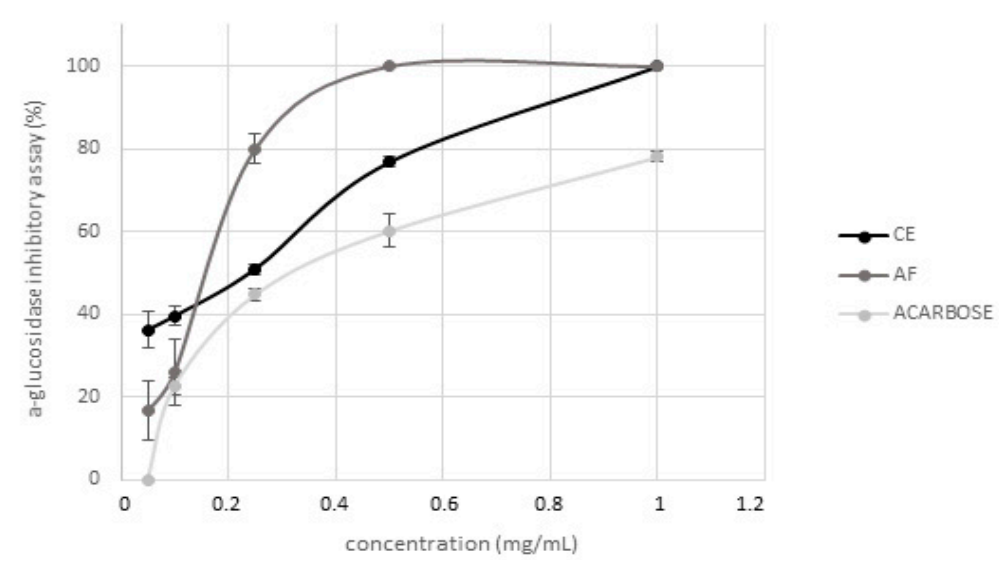

Figure 2. Evaluation of hypoglycemic activity of Moradyn CE and anthocyanin fraction (AF) by $\alpha$-glucosidase inhibition assay; acarbose was used as positive control.

\subsection{Evaluation of Antiglycative Effect Using In Vitro Bovine Serum Albumin-Methylglyoxal, -Glucose,} -Fructose, and -Ribose Systems

Several authors previously reported the antiglycative activity of different plant extracts mainly containing polyphenols $[13,43,46]$; in particular, anthocyanins showed a high effectiveness against protein glycation induced by monosaccharides and methylglyoxal (MGO) [47-49].

The antiglycative properties of CE and AF were investigated by evaluating the inhibition of AGEs formation in the middle and last stages of glycation by BSA-MGO and BSA-sugars assays, respectively.

The capacity of the extract to act in the middle stage of protein glycation was evaluated in the system consisting of BSA and MGO; the inhibition of versperlysine-like AGEs formation at 0.1, 0.25, 0.5 , and $1 \mathrm{mg} / \mathrm{mL}$ after $1,2,3$, and 7 days of incubation was monitored. A dose-response relationship was registered for CE (Figure 3a). The phytocomplex tested at the highest concentration was able to completely prevent the AGEs formation starting from the beginning of the monitoring period and its action is always significantly higher than that of aminoguanidine (AG), used as positive control; conversely, the lowest concentration was able to inhibit only $40-60 \%$ of AGEs. The same trend was registered for $\mathrm{AF}$ when tested at the same concentrations and monitored at the same times. In fact, AF progressively increased its activity until 3 days when values higher than $90 \%$ were reached at all the concentrations with the exception of $0.1 \mathrm{mg} / \mathrm{mL}$ for which a decrease in the antiglycative capacity was registered at the end of the monitoring period (Figure 3b). Considering that the capacity registered for AF was generally similar to the one registered for the corresponding concentration of $\mathrm{CE}$, and that $\mathrm{AF}$ represented only about $28 \%(w / w)$ of the complex, as previously mentioned, it is possible to conclude that AF highly contributed to the global antiglycative capacity in the BSA-MGO system.

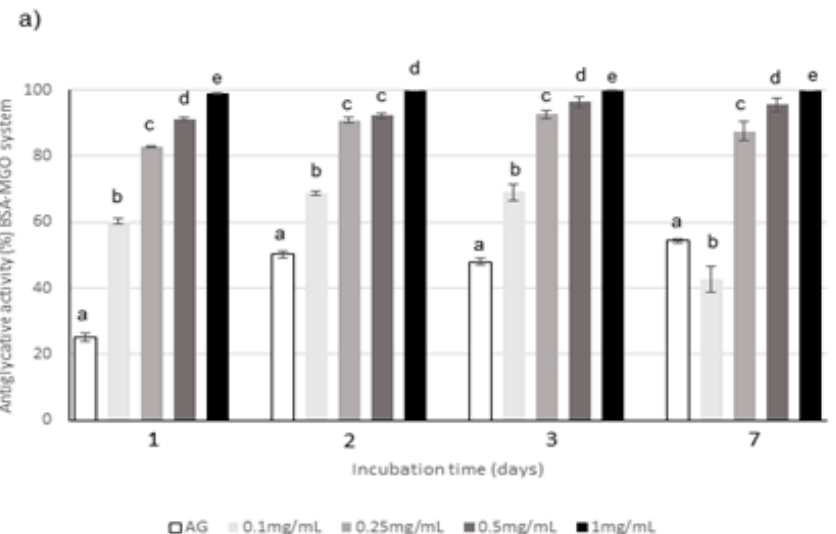

Figure 3. Cont. 
b)

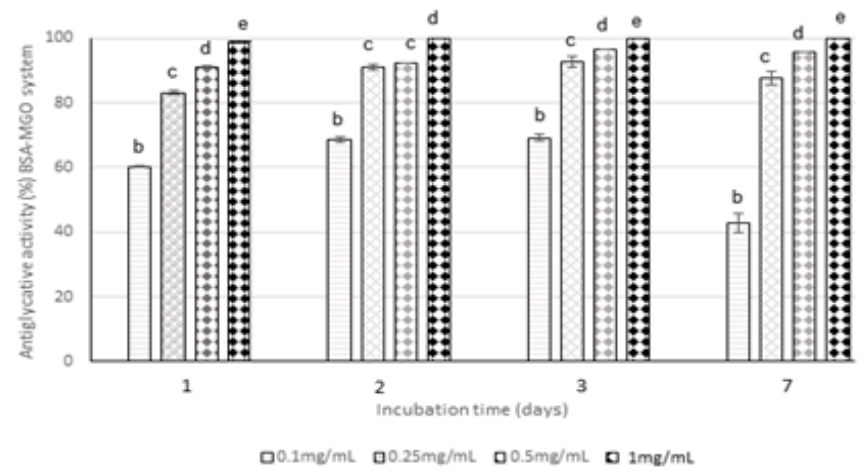

Figure 3. Antiglycative activity of Moradyn CE (a) and AF (b) on the formation of vesperlysine-like advanced glycation end products (AGEs) in BSA-MGO assay; AG, aminoguanidine (positive control). Different superscript letters within each monitoring time indicate significant differences $(p<0.05)$ among $\mathrm{AG}$ and $\mathrm{CE}$ or $\mathrm{AG}$ and $\mathrm{AF}$ at the different tested concentrations.

Regarding BSA-sugar systems, different monitoring times were selected according to the reactivity of each sugar: the glycation kinetics is slower for glucose (GLU), followed by fructose (FRU) and then by ribose (RIB), which is the most reactive sugar. Consequently, the inhibition of AGEs formation was monitored until 28 days, 14 days and $24 \mathrm{~h}$ for GLU, FRU, and RIB, respectively, according to the literature data [50]. The relationship between extract concentration and activity was evaluated through testing four different concentrations, i.e., $0.1,0.25,0.5$, and $1 \mathrm{mg} / \mathrm{mL}$, in all the BSA-sugar systems (Figures 4-6). AG, known to be a potent antiglycative agent, was also used in these assays as positive control. AGEs formation is almost completely inhibited by $1 \mathrm{mg} / \mathrm{mL} \mathrm{CE}$ in all the systems considered at all the monitoring times. Considering $\mathrm{CE}$, the highest activity values were registered in the BSA-GLU system for all the tested concentrations with inhibitory values similar to those registered for AG (Figure 4a). In the BSA-RIB system, a dose-activity relationship was evident and the activity values were always higher than those registered for AG during the entire monitoring period (Figure 5a). A decrease in the AGEs inhibitory capacity was registered when FRU was present, especially for the lowest tested concentration $(0.1 \mathrm{mg} / \mathrm{mL})$ (Figure 6a).

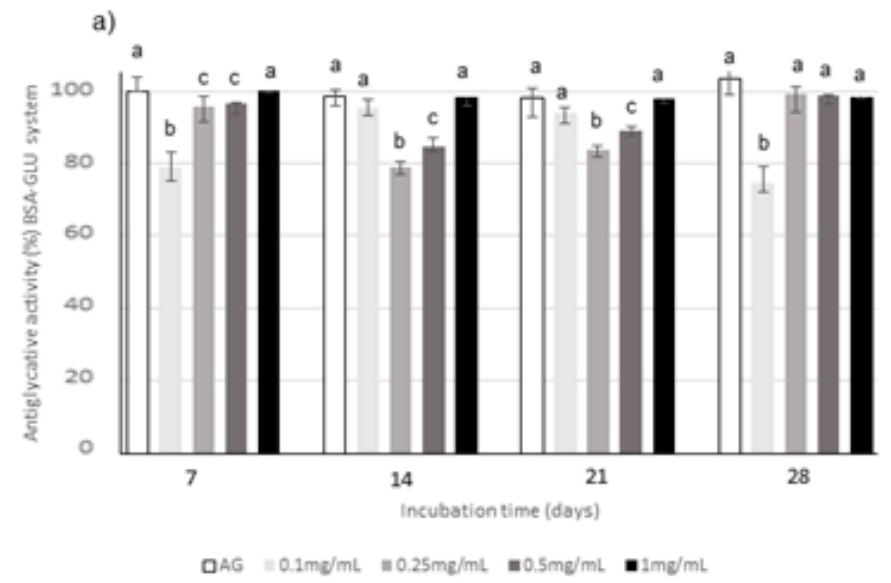

Figure 4. Cont. 


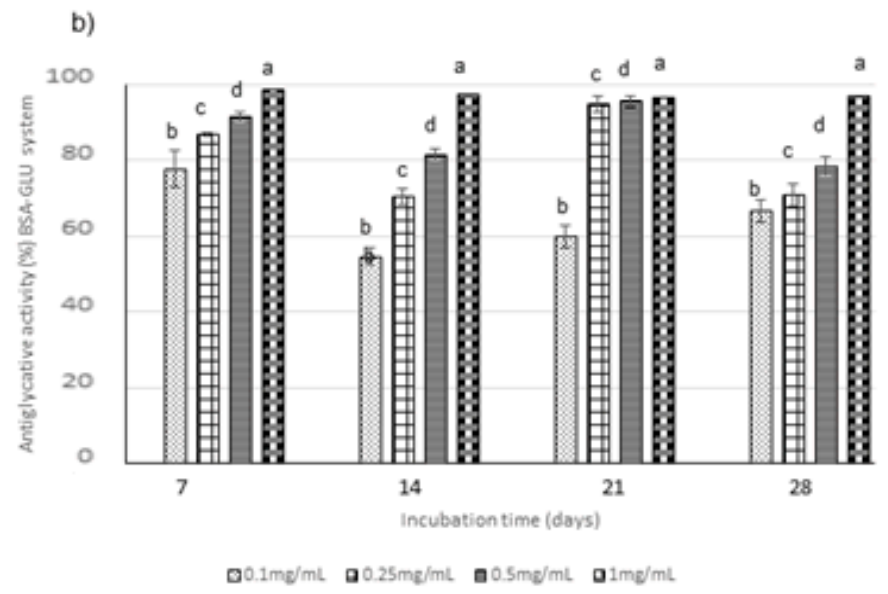

Figure 4. Antiglycative activity of Moradyn CE (a) and AF (b) on the formation of vesperlysine-like AGEs in BSA-GLU assay; AG, aminoguanidine (positive control). Different superscript letters within each monitoring time indicate significant differences $(p<0.05)$ among AG and CE or AG and AF at the different tested concentrations.

a)

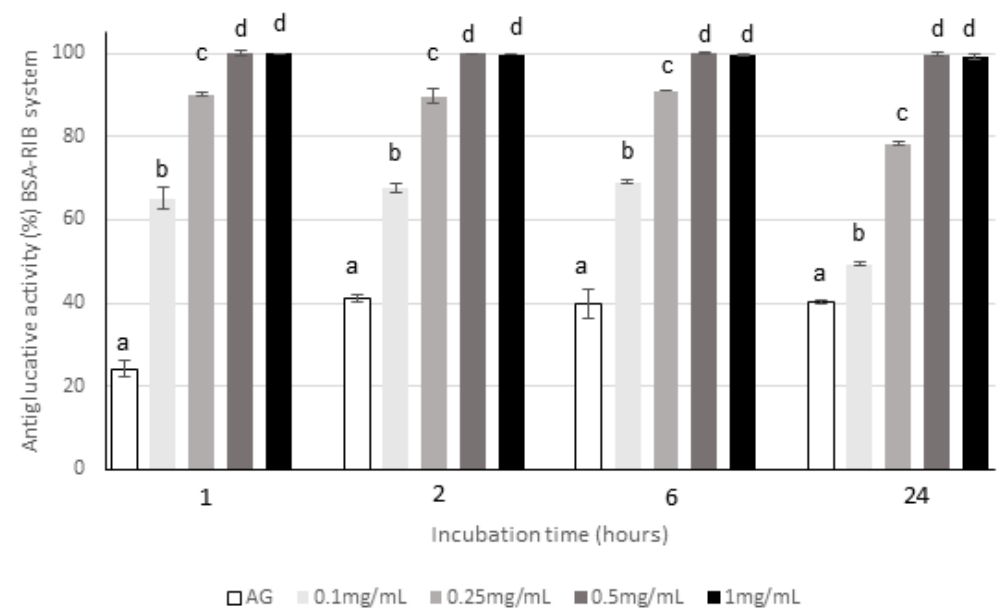

b)

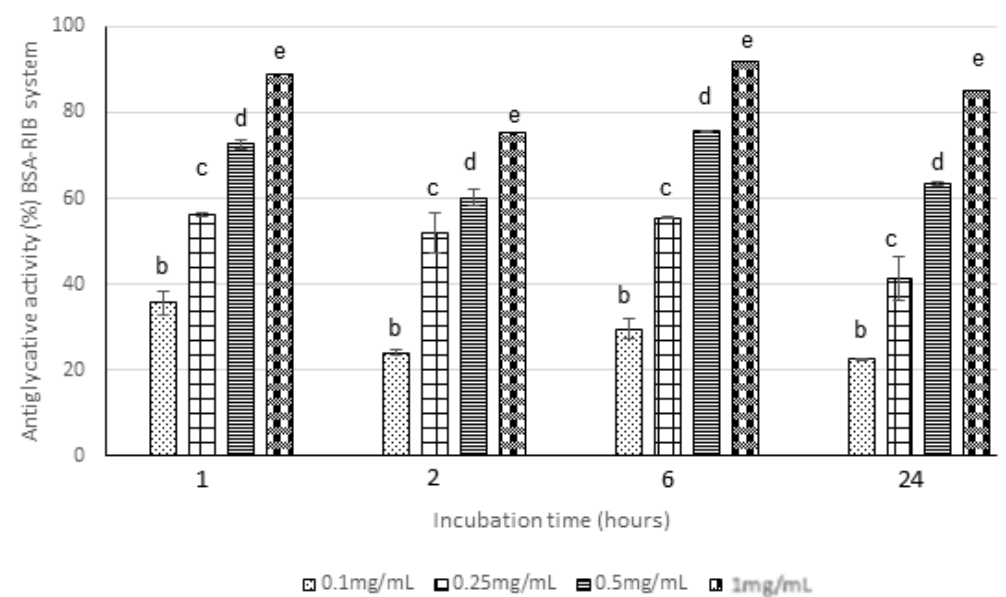

Figure 5. Antiglycative activity of Moradyn CE (a) and AF (b) on the formation of pentosidine-like AGEs in BSA-RIB assay; AG, aminoguanidine (positive control). Different superscript letters within each monitoring time indicate significant differences $(p<0.05)$ among AG and CE or AG and AF at the different tested concentrations. 
a)

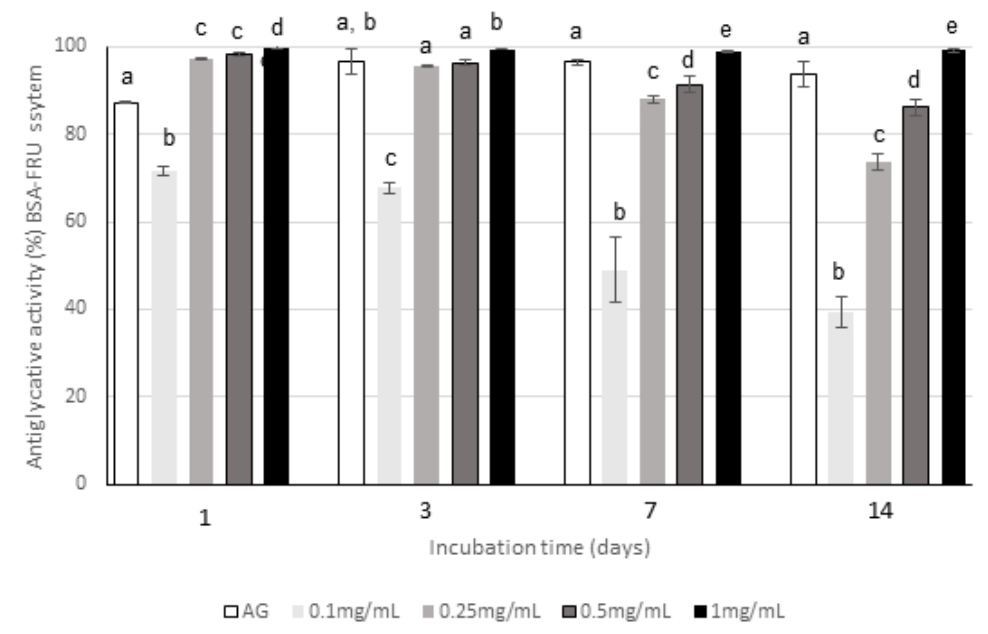

b)

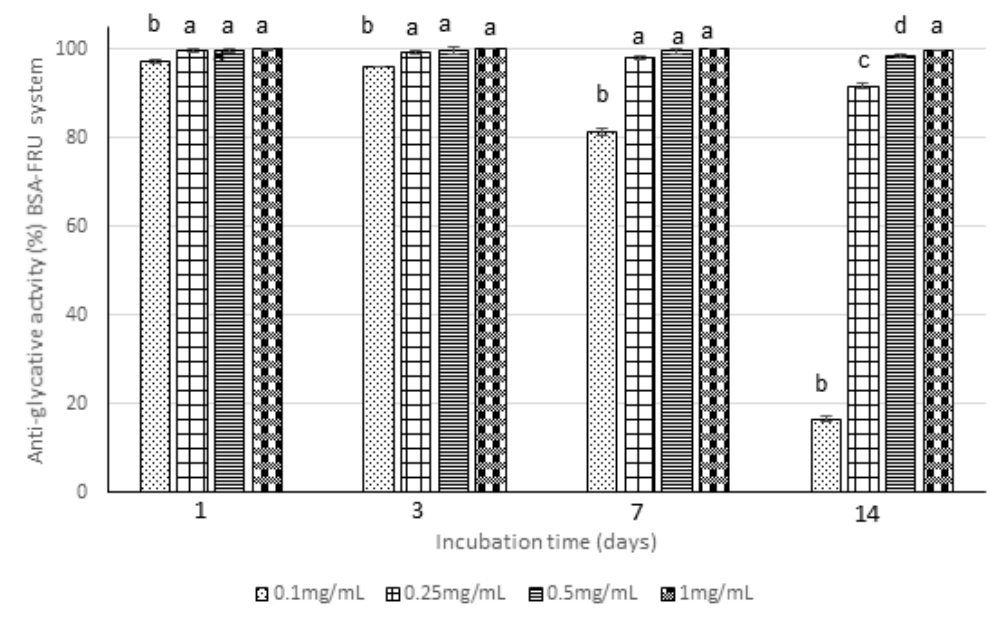

Figure 6. Antiglycative activity of Moradyn CE (a) and AF (b) on the formation of vesperlysine-like AGEs in BSA-FRU assay; AG, aminoguanidine (positive control). Different superscript letters within each monitoring time indicate significant differences $(p<0.05)$ among AG and CE or AG and AF at the different tested concentrations.

The anthocyanin fraction had generally a lower capacity to inhibit AGEs formation in the system containing RIB, even if tested at the same concentration of the phytocomplex. In fact, it reached activity values of about $38 \%$ at $0.1 \mathrm{mg} / \mathrm{mL}$ and of $90 \%$ at $1 \mathrm{mg} / \mathrm{mL}$ (Figure $5 \mathrm{~b}$ ); a decrease in activity was also registered in the GLU system (Figure $4 \mathrm{~b}$ ). Conversely, very high capacity (always higher than $90 \%$ for $0.25-1 \mathrm{mg} / \mathrm{mL}$ ) was detected in the system containing FRU during all the incubation time (Figure $6 \mathrm{~b}$ ).

According to Pearson's correlation coefficient (R2), the correlation between $\alpha$-glucosidase inhibitory activity and antiglycative activity tested with the different assays was always higher than 0.700 for CE over time during the monitoring period, with exception of the BSA-GLU system, highlighting that CE polyphenol composition is strongly related to both $\alpha$-glucosidase inhibitory and antiglycative activities. Considering AF, higher R2 values were always registered probably due to a more marked dose-response relationship (Table 2).

Our antiglycative results are in agreement with the ones previously reported in the literature for berry extracts rich in polyphenols and especially in anthocyanins, which exhibited a strong AGEs inhibitory activity [48]. Moreover, several works also suggested that food byproducts rich in polyphenols are positively correlated with hypoglycemic [51] and antiglycative activities [10,51,52]. 
It is also well known that the different activity values registered for several food matrices and food byproducts are related to the qualitative and quantitative polyphenolic composition. In addition, different chemical structures of such compounds could highly affect the antiglycative activity [46], as confirmed by the results presented here, indicating a higher capacity to prevent AGEs formation for cob extract, which is rich in flavonoids and anthocyanins, than artichoke stem and outer bract extracts, which are rich in previously studied hydroxycinnamic acid derivatives [10].

Table 2. Pearson's correlation coefficients (R2) among $\alpha$-glucosidase inhibitory activity and antiglycative activities monitored at different times of Moradyn CE and AF.

\begin{tabular}{ccc}
\hline Assay & CE $\alpha$-Glucosidase Inhibitory Activity & AF $\alpha$-Glucosidase Inhibitory Activity \\
\hline BSA-MGO system & & \\
1 day & 0.908 & 0.977 \\
2 days & 0.840 & 0.971 \\
3 days & 0.813 & 0.991 \\
7 days & 0.800 & 0.993 \\
BSA-GLU system & & \\
7 day & 0.802 & 0.885 \\
14 days & 0.337 & 0.895 \\
21 days & 0.488 & 0.970 \\
28 days & 0.021 & 0.718 \\
BSA-FRU system & & \\
1 day & 0.728 & 0.984 \\
4 days & 0.745 & 0.987 \\
7 days & 0.803 & 0.982 \\
14 days & 0.915 & 0.983 \\
BSA-RIB system & & \\
1 h & 0.826 & 0.918 \\
3 h & 0.841 & 0.954 \\
6 h & 0.827 & 0.935 \\
24 h & 0.880 & 0.879 \\
\hline
\end{tabular}

\subsection{Bioaccessibility Study}

CE $(1 \mathrm{mg} / \mathrm{mL})$ was digested using an in vitro static approach and the supernatants deriving from each step (oral, gastric, duodenal, and colon) of the process were analyzed by RP-HPLC-UV in order to investigate changes in the chromatographic profile. The chromatograms of undigested and digested CE were recorded both at $520 \mathrm{~nm}$ and $370 \mathrm{~nm}$. Based on LC-MS ${ }^{\mathrm{n}}$ results, 15 different marker compounds were selected in the undigested sample and monitored at each digestion step. In Table 3, the percentage of the relative peak area reduction for each marker was reported. A significant reduction was registered for all the monitored compounds (Figures 7 and 8) mainly due to the gradual dilution of CE following the digestion steps $(0.5 \mathrm{mg} / \mathrm{mL}, 0.25 \mathrm{mg} / \mathrm{mL}, 0.125 \mathrm{mg} / \mathrm{mL}$, and $0.120 \mathrm{mg} / \mathrm{mL}$ in oral, gastric, duodenal, and colon phases, respectively). However, after the oral phase, compounds 4, 6, and 10 were present in lower amounts than expected, according to the dilution trend; for compounds 6 and 10, this behavior could be due to a probable precipitation caused by a complex formation between compounds and enzyme [53-55]; for compound 4, as previously reported by Xiao et al., the presence of a methoxy group on the $\mathrm{B}$ ring in peonidin-3-O-glucoside structure could strengthen the link between $\alpha$-amylase and anthocyanin [56]. On the contrary, after the gastric step, cyanidin-3-O-glucoside and perlagonidin-3-O-glucoside relative abundances were higher than expected. This observation agreed with data already reported in the literature, according to which the strong acidic $\mathrm{pH}$ of the gastric phase and the presence of pepsin caused the anthocyanin bounded fraction release, thus increasing the concentration of each molecule $[57,58]$. Significant changes in the profile were registered after the duodenal step (Figures 7 and 8) for all the peak markers; in particular, the peak area of each anthocyanin was approximately zero, confirming their high instability at basic $\mathrm{pH}[57,59]$. In the colon phase the results were quite similar to those obtained in the duodenal phase (as evident in Table 3), and for this 
reason the chromatograms of the colon step were not reported in Figures 7 and 8 . The above described results agreed with data reported by Chang et al. [60] and by Tavares et al. [61], who assessed the bioaccessibility of cranberry bean and blackberry polyphenols, respectively. In fact, both these works reported an increase in the concentration of the polyphenolic compounds after the gastric phase and a subsequent strong reduction at the end of the intestinal phase, probably due to the interactions of polyphenols with proteins, generally occurring at neutral or basic $\mathrm{pH}$ [60].

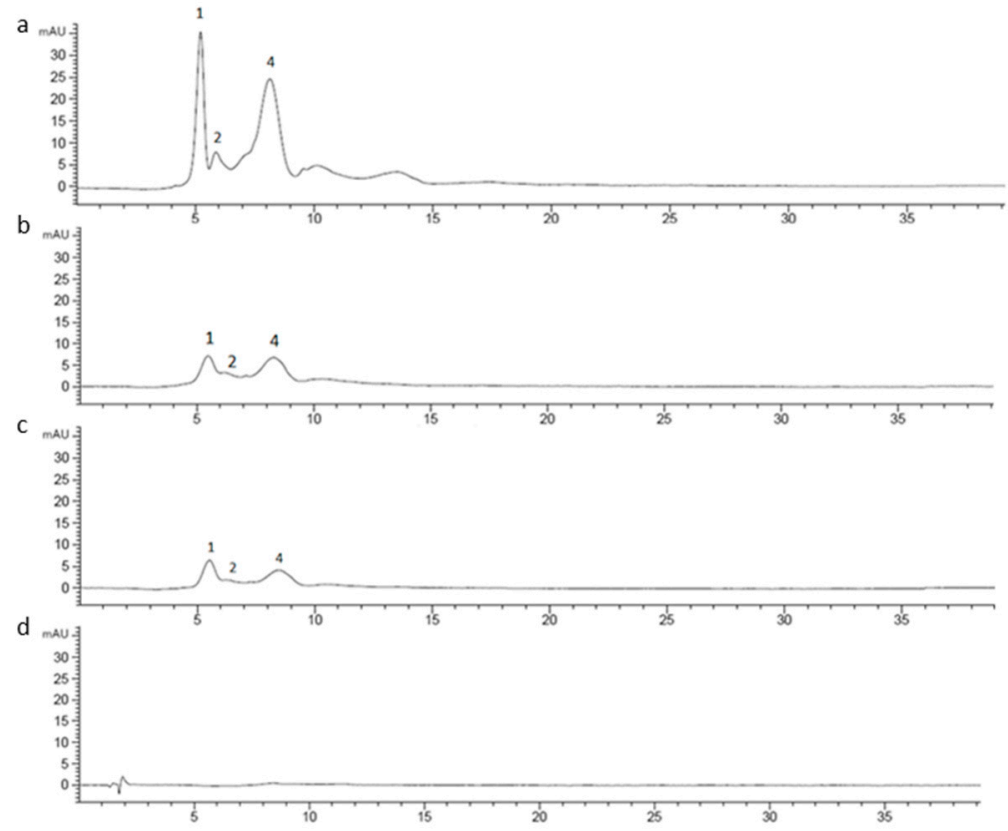

Figure 7. Chromatographic profile of $\mathrm{CE}(1 \mathrm{mg} / \mathrm{mL})(\mathbf{a})$ undigested; (b) after oral phase; (c) after gastric phase; (d) after duodenal phase, registered at $520 \mathrm{~nm}$.

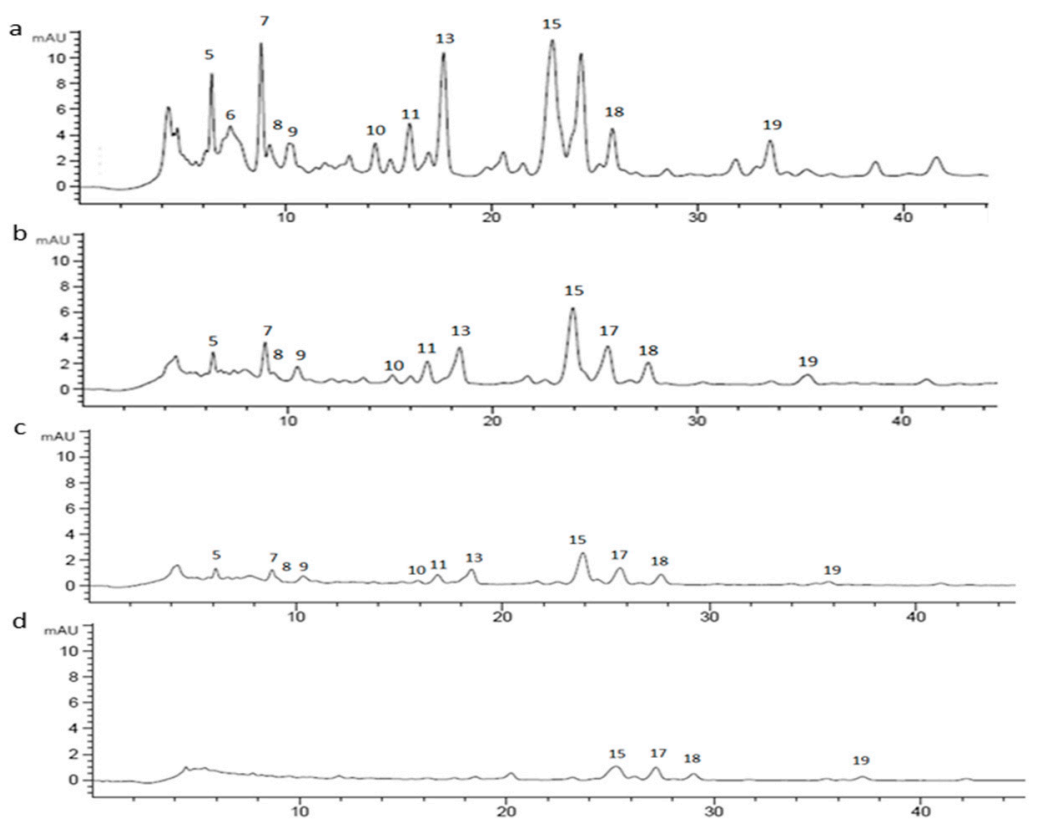

Figure 8. Chromatographic profile of $\mathrm{CE}(1 \mathrm{mg} / \mathrm{mL})(\mathbf{a})$ undigested; (b) after oral phase; (c) after gastric phase; (d) after duodenal phase, registered at $370 \mathrm{~nm}$. 
Table 3. Relative peak area reduction (\%) of CE selected marker compounds after each simulated gastrointestinal digestion step (oral, gastric, duodenal, and colon).

\begin{tabular}{ccccc}
\hline Compound & Oral Phase & Gastric Phase & Duodenal Phase & Colon Phase \\
\hline $\mathbf{1}$ & $63.96 \pm 1.4$ & $69.78 \pm 2.60$ & 100 & 100 \\
$\mathbf{2}$ & $57.86 \pm 0.73$ & $73.33 \pm 1.18$ & 100 & 100 \\
$\mathbf{4}$ & $74.94 \pm 0.78$ & $84.45 \pm 1.94$ & 100 & 100 \\
$\mathbf{5}$ & $61.04 \pm 0.48$ & $80.03 \pm 0.24$ & 100 & 100 \\
$\mathbf{6}$ & 100 & 100 & 100 & 100 \\
$\mathbf{7}$ & $54.97 \pm 0.69$ & $84.54 \pm 0.68$ & 100 & 100 \\
$\mathbf{8}$ & $58.96 \pm 0.87$ & $84.95 \pm 0.26$ & 100 & 100 \\
$\mathbf{9}$ & $48.21 \pm 5.37$ & $72.37 \pm 1.12$ & $95.94 \pm 0.15$ & 100 \\
$\mathbf{1 0}$ & $70.08 \pm 0.10$ & $94.70 \pm 0.90$ & 100 & 100 \\
$\mathbf{1 1}$ & $52.85 \pm 0.05$ & $79.07 \pm 0.25$ & $94.44 \pm 0.37$ & $98.67 \pm 0.32$ \\
$\mathbf{1 3}$ & $56.46 \pm 0.79$ & $82.78 \pm 0.69$ & $93.70 \pm 0.44$ & $98.9 \pm 0.80$ \\
$\mathbf{1 5}$ & $50.64 \pm 1.64$ & $80.67 \pm 0.22$ & $97.95 \pm 0.45$ & $94.99 \pm 0.37$ \\
$\mathbf{1 7}$ & $66.64 \pm 1.30$ & $86.17 \pm 0.14$ & $90.54 \pm 0.24$ & $95.4 \pm 0.24$ \\
$\mathbf{1 8}$ & $45.78 \pm 1.84$ & $73.44 \pm 0.92$ & $83.26 \pm 0.23$ & $86.46 \pm 0.20$ \\
$\mathbf{1 9}$ & $60.53 \pm 2.02$ & $89.44 \pm 0.16$ & 100 & 100 \\
\hline
\end{tabular}

Antiglycative activity of digested samples were evaluated only in BSA-MGO and BSA-GLU systems, considered as the most representative tests. The data are reported in Figures 9 and 10, respectively.

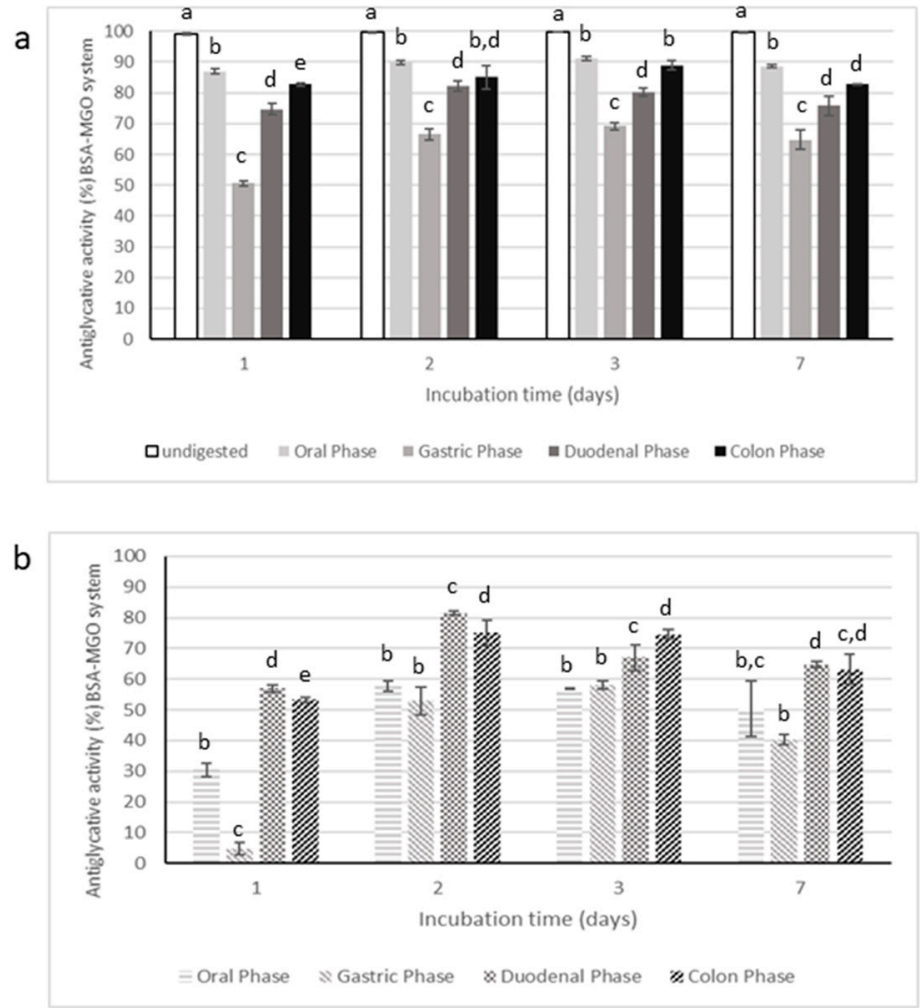

Figure 9. Antiglycative activity of digested Moradyn CE (a) and its negative control (b) on the formation of vesperlysine-like AGEs in BSA-MGO assay. Different superscript letters within each monitoring time indicate significant differences $(p<0.05)$ among undigested and digested CE or undigested CE and digested negative control. 


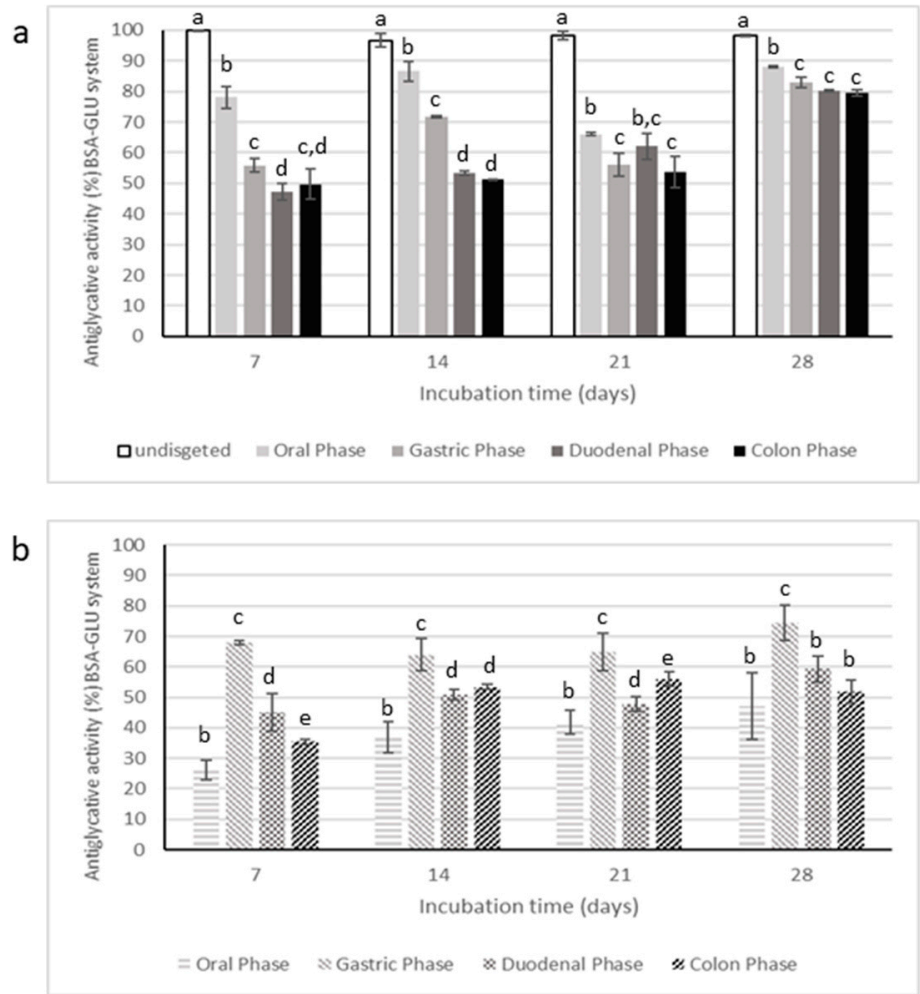

Figure 10. Antiglycative activity of digested Moradyn CE (a) and its negative control (b) on the formation of vesperlysine-like AGEs in BSA-GLU assay. Different superscript letters within each monitoring time indicate significant differences $(p<0.05)$ among undigested and digested CE or undigested $\mathrm{CE}$ and digested negative control.

Digestion strongly affected the inhibitory activity of CE on AGEs formation, starting from the oral phase; in fact, the supernatants collected after this step had significantly lower antiglycative capacity than the undigested CE in BSA-MGO and BSA-GLU systems. The gastric step reduced about 50\% of the inhibitory activity after 1 day of incubation in the BSA-MGO system and then this activity progressively increased over the monitoring time (2,3, and 7 days). Finally, CE activity appeared quite totally recovered after the duodenal and colon phases. This trend was also reported for the negative control, consisting of an appropriate mixture of digestive fluids and enzymes for each phase. Thus, it is possible to speculate that low AGEs formation recorded for CE after the duodenal and colon phases could be due to interactions occurring between MGO and digestive enzymes, leading to non-fluorescent AGEs formations and, therefore, to false positive results.

In the BSA-GLU system, the oral phase did not highly affect the antiglycative capacity. On the contrary, the gastric phase caused a reduction in the inhibitory activity down to about $55 \%$; the following intestinal steps only slightly affected the activity. Nevertheless, considering the inhibitory capacity of the negative control, the antiglycative action of $\mathrm{CE}$ after both gastric and intestinal phases could be mainly associated with interaction between GLU and digestive enzymes, as in the MGO system. Therefore, it is possible to conclude that CE was still effective only after the oral phase.

Hypoglycemic activity of digested $\mathrm{CE}$ was also tested. Inhibitory values registered against $\alpha$-glucosidase $(24.61 \% \pm 1.19 \%, 5.24 \% \pm 2.43 \%, 0.97 \% \pm 1.17 \% 1.37 \% \pm 2.38 \%$ for oral, gastric, duodenal, and colon phase, respectively) highly decreased step by step until the end of the process when CE had no activity. Therefore, digestion seemed to strongly compromise CE hypoglycemic activity as demonstrated by the consistent gradual decrease in the $\alpha$-glucosidase inhibitory capacity occurring during the process. This trend could not be attributed only to the reduction in anthocyanin content, but rather to the decrease in the total polyphenol content. This result confirmed that CE hypoglycemic 
action should be ascribed to the synergistic action of all compounds present in the phytocomplex, as already explained and shown in Figure 2.

\section{Materials and Methods}

\subsection{Reagents}

Ethanol, methanol, D-(+)-glucose (GLU), D-(-)-fructose (FRU), disodium hydrogen phosphate dodecahydrate, sodium carbonate decahydrate and sodium bicarbonate were purchased from Carlo Erba (Milano, Italy). HPLC-MS-grade formic acid and acetonitrile, hydrochloric acid (37\%), Type VI-porcine pancreatic $\alpha$-amylase, $\alpha$-glucosidase from Saccharomices cerevisiae, pepsin from porcine gastric mucosa $\left(\geq 400 \mathrm{U} \mathrm{mg}^{-1}\right)$, bile extract porcine, pancreatin $(8 \times \mathrm{USP})$ from porcine pancreas, protease from Streptomyces griseus type XIV $\left(\geq 3.5 \mathrm{U} \mathrm{mg}^{-1}\right)$, and viscozyme L cellulolytic enzyme mixture, $p$-nitrophenyl-alpha-D-glucopyranoside (purity grade $\geq 99 \%$ ), starch, acarbose (purity grade $\geq 95 \%$ ), sodium potassium tartrate tetrahydrate, dinitrosalicylic acid (DNS), methylglyoxal (MGO, 40\% aqueous solution), aminoguanidine hydrochloride (AG, purity grade $\geq 98 \%$ ), bovine serum albumin (BSA, purity grade $\geq 98 \%$ ), D-(-)-ribose (RIB, purity grade $\geq 98 \%$ ), sodium dihydrogen phosphate monohydrate, disodium hydrogen phosphate monohydrate, sodium hydroxide pellets, sodium chloride, sodium azide (purity grade 99.5\%), pelargonidin-3-O-glucoside, apigenin-7-O-glucoside, and quercetin-7-O-glucoside were provided by Merck KGaA (Darmstadt, Germany).

Water was obtained from a Millipore Direct-QTM system (Merck-Millipore, Milan, Italy). Kuromanin chloride (cyanidin-3-O-glucoside), peonidin-3-O-glucoside, kaempferol-7-O-glucoside, and luteolin-7-O-glucoside were purchased from Extrasynthese (Genay, Rhone, France).

Sep-Pak C18 cartridges (6 mL, 1 g sorbent) were purchased from Waters Corporation (Massachussets, MA, USA).

\subsection{Moradyn Cob Extract Preparation}

The Moradyn population has been developed in Italy (Lombardy region, 2015-2018) starting from a cross hybrid morado variety (South America) by a pedigree selection of photoperiod, seed, and cob pigmentation. This variety has been submitted to the Community Plant Variety Office for the registration (Examination Ref. 4067062) by FlaNat Research Italia Srl. Moradyn cobs were chopped into small pieces (about 1-2 cm) and extracted by FlaNat Research Italia S.r.l. (Milan, Italy) with aqueous ethanol for $3 \mathrm{~h}$ at $50^{\circ} \mathrm{C}$. The resulting suspension was filtered through $0.45 \mu \mathrm{m}$ membrane filters (Merck-Millipore, Milan, Italy) and after removing organic solvent under reduced pressure at $40^{\circ} \mathrm{C}$ (Buchi R-II, Buchi, UK), the cob extract (CE) was freeze-dried (Modulyo freeze-drier s/n 5101, Akribis scientific limited, Cheshire, UK) and then used in the experiments.

\subsection{Anthocyanin Fraction Purification}

Anthocyanin fraction (AF) isolation was performed using a Sep-Pak C18 cartridge, following the procedure reported by Scorrano et al. [62] with some modifications. The cartridge was activated with $10 \mathrm{~mL}$ of methanol followed by $20 \mathrm{~mL}$ of acidified water $(0.01 \% v / v \mathrm{HCl})$. Then, $5 \mathrm{~mL}$ of ten-fold concentrated extract was loaded. After having removed sugars and phenolic acids with $10 \mathrm{~mL}$ of acidified water and less polar compounds with $10 \mathrm{~mL}$ of ethyl acetate, AF was collected with $10 \mathrm{~mL}$ of acidified methanol $(0.01 \% v / v \mathrm{HCl})$. The recovered $\mathrm{AF}$ was evaporated to remove solvent and then freeze-dried, obtaining a ready-to-use powder to be opportunely re-suspended for each assay.

\subsection{RP-HPLC-DAD-ESI-MS ${ }^{n}$ Analysis}

Separation and identification of compounds present in the phytocomplex were performed using a Thermo Finningan Surveyor Plus HPLC apparatus (Thermo Fischer Scientific, Waltham, MA, USA) equipped with a quaternary pump, a Surveyor UV-Vis photodiode-array detector, a Surveyor Plus autosampler, and a vacuum degasser connected to a LCQ Advantage Max ion trap spectrometer 
through an ESI source. A Gemini ${ }^{\circledR}$ C18 analytical column $(150 \times 2.0 \mathrm{~mm}$ i.d., $5 \mu \mathrm{m}$, Phenomenex, Torrance, CA, USA) operating at a constant flow rate of $0.3 \mathrm{~mL} / \mathrm{min}$ (injection volume $20 \mu \mathrm{L}$ ) was used for the separation. The mobile phase consisted of $0.1 \%$ formic acid aqueous solution (solvent $\mathrm{A}$ ) and of $0.1 \%$ formic acid in acetonitrile (solvent $\mathrm{B}$ ) with the following gradient table: $0-3 \mathrm{~min}, 2-15 \% \mathrm{~B}$; 3-45 min, $15-25 \%$ B; 45-48 min, 25-35\% B; 48-58 min, 2\% B, column reconditioning: $10 \mathrm{~min}$. UV-Vis spectral data of samples were acquired in the range $200-700 \mathrm{~nm}$, and chromatograms were recorded at $280,325,370$, and $520 \mathrm{~nm}$.

The parameters of the ion mode ESI source had previously been optimized to a ionization voltage of $5 \mathrm{kV}$, a capillary voltage of $+36 \mathrm{~V}$, a capillary temperature of $300{ }^{\circ} \mathrm{C}$, a sheath gas flow rate of 20 arbitrary units (AU), and an auxiliary gas flow rate of $10 \mathrm{AU}$. The Thermo Fisher Scientific Excalibur 2.2 software was used for data acquisition and processing. The ion trap operated in data-dependent, full scan $(60-2000 \mathrm{~m} / \mathrm{z})$, and $\mathrm{MS}^{\mathrm{n}}$ mode to obtain fragment ion $\mathrm{m} / \mathrm{z}$ with a $35 \%$ and an isolation width of $3 \mathrm{~m} / \mathrm{z}$. Three independent assays were performed. Identification of individual phenolic compounds was carried out by comparing their retention times, UV-Vis spectra, and MS patterns of fragmentation with those obtained for original standards, when commercially available.

\subsection{Evaluation of Hypoglycemic Activity}

Both $\mathrm{CE}$ and $\mathrm{AF}$ were tested at different concentrations (ranging from $50 \mu \mathrm{g} / \mathrm{mL}$ to $1 \mathrm{mg} / \mathrm{mL}$ ) to evaluate their ability to inhibit $\alpha$-amylase and $\alpha$-glucosidase activities. CE digestion fractions were tested only for $\alpha$-amylase inhibitory activity. Data were expressed as the means \pm standard deviation (SD) of four independent experiments for each tested concentration. They were considered statistically significant with $p$ values $<0.05$.

\subsection{1. $\alpha$-Amylase Inhibitory Activity}

The $\alpha$-amylase inhibition assay was performed following the method reported by Milella et al. [41] with some modifications. Briefly, $500 \mu \mathrm{L}$ of Type VI-B porcine pancreatic $\alpha$-amylase $(0.5 \mathrm{mg} / \mathrm{mL}$ in $100 \mathrm{mM}$ sodium phosphate buffer, containing $6.7 \mathrm{mM}$ sodium chloride, $\mathrm{pH}$ 6.7-PBS) were preincubated with $500 \mu \mathrm{L}$ of each sample (CE or AF) in test tubes at $37^{\circ} \mathrm{C}$ for $10 \mathrm{~min}$. Then, $500 \mu \mathrm{L}$ of $1 \%$ starch ( $w / v$, previously suspended in $100 \mathrm{mM}$ PBS, $\mathrm{pH}$ 6.7, and boiled for $10 \mathrm{~min}$ ) was added. This mixture was incubated for $10 \mathrm{~min}$. Finally, $1 \mathrm{~mL}$ of DNS reagent (consisting of $20 \mathrm{~mL}$ of $96 \mathrm{mM}$ DNS, $8 \mathrm{~mL}$ of $5.315 \mathrm{M}$ sodium potassium tartrate tetrahydrate in $2 \mathrm{M} \mathrm{NaOH}$ and $12 \mathrm{~mL}$ of distilled water) was added. The tubes were placed in a boiling water bath $(5 \mathrm{~min})$ to stop the reaction, then cooled at room temperature and diluted with $10 \mathrm{~mL}$ of distilled water. DNS reacted with free reducing sugars released by enzymatic hydrolysis of starch, leading to a change in the color of the sample (from yellow to deep red). Absorbance was read at $520 \mathrm{~nm}$. In order to remove the background signals, the absorbances of all samples were also registered in absence of the enzyme solution. Sample made of only starch and enzyme solution were used as a negative control while acarbose solutions (ranging from $5 \mu \mathrm{g} / \mathrm{mL}$ to $100 \mu \mathrm{g} / \mathrm{mL}$ ) were used as a positive control.

The results were expressed as $\alpha$-amilase inhibition percentage, calculated using the following formula:

Inhibition rate $(\%)=[1-($ Abs $520 \mathrm{~nm}$ sample - Abs $520 \mathrm{~nm}$ background/Abs $520 \mathrm{~nm}$ negative control)] $\times 100$

\subsection{2. $\alpha$-Glucosidase Inhibitory Activity}

The capacity of the tested samples to inhibit $\alpha$-glucosidase activity was performed according to method proposed by Flores et al. [42] with slight modifications. A total of $100 \mu \mathrm{L}$ of $\alpha$-glucosidase solution $(0.35 \mathrm{U} / \mathrm{mL} 100 \mathrm{mM}$ PBS, pH 6.7) was incubated with $50 \mu \mathrm{L}$ of sample solution for $10 \mathrm{~min}$ at $37^{\circ} \mathrm{C}$ in a test tube. Then, $100 \mu \mathrm{L}$ of $1.5 \mathrm{mM}$ p-nitrophenyl- $\alpha$-D-glucopyranoside solution (an artificial substrate which released a yellowish phenolic compound when hydrolyzed by $\alpha$-glucosidase) was added and the final mixture was left for $20 \mathrm{~min}$ at $37^{\circ} \mathrm{C}$. The reaction was stopped by adding $1 \mathrm{~mL}$ $1 \mathrm{M}$ sodium carbonate decahydrate and the absorbance was read at $400 \mathrm{~nm}$. 
Samples without the enzyme solution were used as blank. A mixture containing all reactants was used as a negative control. Acarbose solutions $(0.05-1 \mathrm{mg} / \mathrm{mL})$ were used as a positive control.

The results were expressed as $\alpha$-glucosidase inhibition percentage, calculated using the following formula:

Inhibition rate $(\%)=[1-($ Abs $400 \mathrm{~nm}$ mixture containing sample - Abs $400 \mathrm{~nm}$ blank/Abs $400 \mathrm{~nm}$ negative control) $] \times 100$

\subsection{Evaluation of Antiglycative Capacity}

The antiglycative properties of both $\mathrm{CE}$ and its AF were evaluated by using three different in vitro BSA-sugars systems (glucose, GLU; ribose, RIB; fructose, FRU) and a BSA-MGO system, following the methods proposed by Mesìas et al. [11] and by Maietta et al. [63], slightly modified. In all systems, AG was used as positive control. Conversely, digested CE supernatants were tested only in BSA-GLU and BSA-MGO assays.

Stock solutions were prepared by dissolving BSA (35 mg/mL), GLU (175 mg/mL), RIB (150 mg/mL), FRU $(175 \mathrm{mg} / \mathrm{mL}), \mathrm{MGO}(0.4 \mathrm{mg} / \mathrm{mL})$, and AG $(0.5 \mathrm{mg} / \mathrm{mL})$ in $0.1 \mathrm{M}$ phosphate buffer $(\mathrm{pH} 7.4)$ containing $0.02 \%(w / v)$ of sodium azide (to avoid microbial contamination). Sample solutions were prepared by dissolving freeze-dried material in a proper volume of phosphate buffer to obtain $0.1,0.25$, and $1 \mathrm{mg} / \mathrm{mL}$ final concentrations in the reaction mixtures. Then, $400 \mu \mathrm{L}$ of BSA solution, $800 \mu \mathrm{L}$ of sugar solution, and $300 \mu \mathrm{L}$ of sample solution or phosphate buffer (blank) were mixed and the final reaction mixture was subsequently incubated at $37^{\circ} \mathrm{C}$ in a thermostatted bath (Memmert basic WNB, Schwabach, Germany).

The systems were incubated for different times depending on sugars and MGO reactivity [64], as follows: GLU systems were incubated for 28 days, monitoring AGEs formation once a week, while systems containing MGO and FRU for 7 and 14 days, respectively, with analytical determination at 1, 3, 7 , and 14 days. Samples containing RIB were incubated for $24 \mathrm{~h}$ evaluating the AGEs formation at 1, 3, 6 , and $24 \mathrm{~h}$. At the end of each monitored time, the reaction was stopped in an ice bath (15 min) before the analysis. Vesperlysine-like $\left(\lambda_{\text {exc }} 370 \mathrm{~nm}, \lambda_{\text {em }} 440 \mathrm{~nm}\right)$ or Pentosidine-like $\left(\lambda_{\text {exc }} 335 \mathrm{~nm} ; \lambda_{\text {em }} 420 \mathrm{~nm}\right)$ fluorescent AGEs (Spectrofluorometer Perkin Elmer L550B) were monitored for BSA-GLU, BSA-FRU, and BSA-MGO systems, or for BSA-RIB, respectively. CE and AF phosphate buffer solutions were incubated at the same reaction times to evaluate their intrinsic fluorescence.

The inhibition of AGE formation (\%) was calculated using the equation below:

Inhibition $\%=[1-$ (Fluorescence of incubation mixture containing sample - Intrinsic fluorescence of sample/Fluorescence of incubation mixture without sample) $] \times 100$

The reported data are the means \pm standard deviation (SD) of three independent experiments for each tested concentration, each performed in triplicate. They were considered statistically significant with $p$ values of $<0.05$.

\subsection{In Vitro Digestion Procedure}

The in vitro gastrointestinal digestion model was designed following the INFOGEST protocol [65], with some modifications; briefly, simulated salivary fluid (SSF), simulated gastric fluid (SGF), and simulated intestinal fluid (SIF) were basically prepared with electrolytes, enzymes, bile salts, and water; pepsin and pancreatin were added to SGF and SIF, respectively, while the colon phase was simulated according to Hamzalığlu procedure [66]. At the end of each step, enzymes were inactivated $\left(90{ }^{\circ} \mathrm{C}, 5 \mathrm{~min}\right.$ ) and digestion mixtures were centrifuged $\left(30 \mathrm{~min}, 4^{\circ} \mathrm{C}, 5000 \mathrm{rpm}\right.$, Centrifuge $5804 \mathrm{R}$ Eppendorf). Supernatants were freeze-dried and stored at $-20^{\circ} \mathrm{C}$ until analyses.

A total of $1 \mathrm{mg} / \mathrm{mL}$ aqueous CE solution was digested, while the negative control consisted of an aqueous solution of digestion fluids and enzymes submitted to the same four-step procedure. 


\subsection{Bioaccessibility Evaluation}

The percentage of soluble polyphenols collected at the end of each digestion step represents the CE fraction available for absorption [29,58].

To monitor the gastrointestinal effects on CE composition, the oral, gastric, duodenal, and colon fractions were analyzed using an Agilent Technologies 1260 Infinity II technology series system (Santa Clara, CA, USA), equipped with quaternary gradient pump, a vial sampler, a degasser, a thermostatted column oven set at $25.0 \pm 0.5{ }^{\circ} \mathrm{C}$, and a variable wavelength detector (VWD). The HPLC-VWD system was controlled using a personal computer equipped with Agilent OpenLab CDS ChemStation software on Windows 10. Separation was carried out on the same column and using the same gradient elution reported for RP-HPLC-DAD-ESI-MSn analysis (Section 3.4). Chromatograms were recorded at $520 \mathrm{~nm}$ and $370 \mathrm{~nm}$.

Furthermore, supernatants obtained by each digestion step were also tested for their antiglycative capacity using BSA-MGO and BSA-GLU systems and for hypoglycemic activity, assessed as $\alpha$-glucosidase inhibitory activity.

\subsection{Statistical Analysis}

Statistical analysis of the data and Pearson's correlation coefficients were performed using Microsoft Office 365. The significant differences $(p<0.05)$ were evaluated by variance analysis (ANOVA).

\section{Conclusions}

The reuse of agro-industrial byproducts represents a very important issue in the circular bio-economy and a potential resource of new products and compounds. Moradyn is a new Italian purple corn variety rich in polyphenols, including anthocyanin derivatives, such as cyanidin-3-O-glucoside, perlagonidin-3-O-glucoside, and peonidin-3-O-glucoside. It was demonstrated to possess a good capacity to inhibit $\alpha$-glucosidase in an in vitro system and therefore it could act in blocking the intestinal carbohydrate-digesting enzyme activity.

Moreover, Moradyn phytocomplex could prevent AGEs formation, acting with a strong antiglycative agent as demonstrated in this work using in vitro model systems. The registered healthy effects were not only due to anthocyanin fraction, but more probably to a synergistic action of all polyphenols present in the extract. A further step consisting of the evaluation of bioaccessibility of Moradyn CE indicated that the in vitro digestion process caused a marked decrease in the tested bioactivities. These results highlight that such studies are mandatory to obtain preliminary information useful for proceeding with the selection of suitable coating agents in order to preserve bioactivities. Moreover, once the carrier has been selected, stability studies on the final ingredient to be marketed and efficacy on glucose uptake and adipogenesis using cell-based assays will be performed.

Author Contributions: Conceptualization, A.P. and R.C.; methodology, L.F.; formal analysis, L.F. and B.M.; investigation, A.P., R.C. and L.F.; writing-original draft preparation, A.P., R.C. and L.F.; writing-review and editing, A.P. and R.C., supervision, A.P. All authors have read and agreed to the published version of the manuscript.

Funding: This research received no external funding.

Conflicts of Interest: The authors declare no conflict of interest.

\section{References}

1. Lao, F.; Giusti, M. Quantification of purple corn (Zea mays L.) anthocyanins using spectrophotometric and HPLC approaches: Method comparison and correlation. Food Anal. Met. 2016, 9, 1367-1380. [CrossRef]

2. Yonemaru, J.; Miki, K.; Choi, S.; Kiyosawa, A.; Goto, K. A genomic region harboring the Pl1 allele from the Peruvian cultivar JC072A confers purple cob on Japanese flint corn (Zea mays L.). Breed. Sci. 2018, 68, 582-586. [CrossRef] 
3. Chatham, L.A.; West, L.; Berhow, M.A.; Vermillion, K.E.; Juvik, J.A. Unique flavanol-anthocyanin condensed forms in Apache red purple corn. J. Agric. Food Chem. 2018, 66, 10844-10854. [CrossRef] [PubMed]

4. Khamphasan, P.; Lomthaisong, K.; Harakotr, B.; Ketthaisong, D.; Scott, M.P.; Lertrat, K.; Suriharn, B. Genotypic variation in anthocyanins, phenolic compounds, and antioxidant activity in cob and husk of purple field corn. Agronomy 2018, 8, 271. [CrossRef]

5. Li, C.Y.; Kim, H.W.; Won, S.R.; Min, H.; Park, K.J.; Park, J.Y.; Ahn, M.S.; Rhee, H.I. Corn husk as a potential source of anthocyanins. J. Agric. Food Chem. 2008, 56, 11413-11416. [CrossRef] [PubMed]

6. Li, Q.; Somavat, P.; Singh, V.; Chatham, L.; Gonzalez de Mejia, E. A comparative study of anthocyanin distribution in purple and blue corn coproducts from three conventional fractionation processes. Food Chem. 2017, 231, 332-339. [CrossRef]

7. Jing, P.; Giusti, M. Characterization of anthocyanin-rich waste from purple corncobs (Zea mays L.) and its application to color milk. J. Agric. Food Chem. 2005, 53, 8775-8781. [CrossRef]

8. Pascual-Teresa, S.; Santos-Buelga, C.; Rivas-Gonzalo, J. LC-MS analysis of anthocyanins from purple corn cob. J. Sci. Food Agric. 2002, 82, 1003-1006. [CrossRef]

9. Cuevas Montilla, E.; Hillebrand, S.; Antezana, A.; Winterhalter, P. Soluble and bound phenolic compounds in different Bolivian purple corn (Zea mays L.) cultivars. J. Agric. Food Chem. 2011, 59, 7068-7074. [CrossRef]

10. Žilić, S.; Serpen, A.; Akıllıŏlu, G.; Gökmen, V.; Vančetovic, J. Phenolic compounds, carotenoids, anthocyanins, and antioxidant capacity of colored maize (Zea mays L.) kernels. J. Agric. Food Chem. 2012, 60, 1224-1231. [CrossRef]

11. Maietta, M.; Colombo, R.; Lavecchia, R.; Sorrenti, M.; Zuorro, A.; Papetti, A. Artichoke (Cynara cardunculus L. var. scolymus) waste as a natural source of carbonyl trapping and antiglycative agents. Food Res. Int. 2017, 100, 780-790. [CrossRef] [PubMed]

12. Mesías, M.; Navarro, M.; Gökmen, V.; Morales, F.J. Antiglycative effect of fruit and vegetable seed extracts: Inhibition of AGE formation and carbonyl-trapping abilities. J. Sci. Food Agric. 2013, 93, 2037-2044. [CrossRef]

13. Navarro, M.; Fiore, A.; Fogliano, V.; Morales, F.J. Carbonyl trapping and antiglycative activities of olive oil mill wastewater. Food Funct. 2015, 6, 574-583. [CrossRef] [PubMed]

14. Sri Harsha, P.S.C.; Lavelli, V.; Scarafoni, A. Protective ability of phenolics from white grape vinification by-products against structural damage of bovine serum albumin induced by glycation. Food Chem. 2014, 156, 220-226. [CrossRef] [PubMed]

15. Navarro, M.; Morales, F.J. Evaluation of an olive leaf extract as a natural source of antiglycative compounds. Food Res. Int. 2017, 92, 56-63. [CrossRef] [PubMed]

16. Dobler, D.; Ahmed, N.; Song, L.; Eboigbodin, K.E.; Thornalley, P.J. Increased dicarbonyl metabolism in endothelial cells in hyperglycemia induces anoikis and impairs angiogenesis by RGD and GFOGER motif modification. Diabetes 2006, 55, 1961-1969. [CrossRef]

17. Kuhla, A.; Ludwig, S.C.; Kuhla, B.; Münch, G.; Vollmar, B. Advanced glycation end products are mitogenic signals and trigger cell cycle reentry of neurons in Alzheimer's disease brain. Neurobiol. Aging 2015, 36, 753-761. [CrossRef]

18. Wetzels, S.; Wouters, K.; Schalkwijk, C.G.; Vanmierlo, T.; Hendriks, J.J.A. Methylglyoxal-derived advanced glycation endproducts in multiple sclerosis. Int. J. Mol. Sci. 2017, 18, 421. [CrossRef]

19. Zhang, Q.; Ames, J.M.; Smith, R.D.; Baynes, J.W.; Metz, T.O. A Perspective on the Maillard reaction and the analysis of protein glycation by mass spectrometry: Probing the pathogenesis of chronic disease. J. Proteome Res. 2009, 8, 754-769. [CrossRef]

20. Chen, C.; Somavat, P.; Singh, V.; Gonzalez de Mejia, E. Chemical characterization of proanthocyanidins in purple, blue, and red maize coproducts from different milling processes and their antiinflammatory properties. Ind. Crops Prod. 2017, 109, 464-475. [CrossRef]

21. Ramos-Escudero, F.; MunõZ, A.M.; Alvarado-Ortì, C.; Alvarado, A.; Yánez, J.A. Purple corn (Zea mays L.) phenolic compounds profile and its assessment as an agent against oxidative stress in isolated mouse organs. J. Med. Food 2012, 15, 206-215. [CrossRef] [PubMed]

22. Thilavech, T.; Ngamukote, S.; Abeywardena, M.; Adisakwattana, S. Protective effects of cyanidin-3-rutinoside against monosaccharides-induced protein glycation and oxidation. Int. J. Biol. Macromol. 2015, 75, 515-520. [CrossRef] [PubMed] 
23. Yang, Z.; Zhai, W. Identification and antioxidant activity of anthocyanins extracted from the seed and cob of purple corn (Zea mays L.). Innov. Food Sci. Emerg. Technol. 2010, 11, 169-176. [CrossRef]

24. Chaiittianana, R.; Sutthanutb, K.; Rattanathongkomc, A. Purple corn silk: A potential anti-obesity agent with inhibition on adipogenesis and induction on lipolysis and apoptosis in adipocytes. J. Ethnopharmacol. 2017, 201, 9-16. [CrossRef]

25. Guzmán-Gerónimo, R.I.; Alarcón-Zavaleta, T.M.; Oliart-Ros, R.M.; Meza-Alvarado, J.E.; Herrera-Meza, S.; Chávez-Servia, J.L. Blue maize extract improves blood pressure, lipid profiles, and adipose tissue in high-sucrose diet-induced metabolic syndrome in rats. J. Med. Food 2017, 20, 110-115. [CrossRef]

26. Luna-Vital, D.; Weiss, M.; Gonzalez de Mejia, E. Anthocyanins from purple corn ameliorated TNF- $\alpha$-induced inflammation and insulin resistance in 3T3-L1 adipocytes via activation of insulin signaling and enhanced GLUT4 translocation. Mol. Nutr. Food Res. 2017, 61, 1700362-1700375. [CrossRef]

27. Lago, C.; Cassani, E.; Zanzi, C.; Landoni, M.; Trovato, R.; Pilu, R. Development and study of a maize cultivar rich in anthocyanins: Coloured polenta, a new functional food. Plant Breed. 2014, 113, 210-217. [CrossRef]

28. Petroni, K.; Pilu, R.; Tonelli, C. Anthocyanins in corn: A wealth of genes for human health. Planta 2014, 240, 901-911. [CrossRef]

29. Morales-Ortega, A.; Carvajal-Millan, E.; Brown-Bojorquez, F.; Rascón-Chu, A.; Patricia Torres-Chavez, P.; López-Franco, Y.L.; Lizardi-Mendoza, J.; Martínez-López, A.L.; Campa-Mada, A.C. Entrapment of probiotics in water extractable arabinoxylan gels: Rheological and microstructural characterization. Molecules 2014, 19, 3628-3637. [CrossRef]

30. McClements, D.J.; Li, F.; Xiao, H. The nutraceutical bioavailability classification scheme: Classifying nutraceuticals according to factors limiting their oral bioavailability. Annu. Rev. Food Sci. Technol. 2015, 6, 299-327. [CrossRef]

31. Lima, K.; Silva, O.; Figueira, M.E.; Piresa, C.; Cruza, D.; Gomes, S.; Muchagato, E.M.; Duartea, M.P. Influence of the in vitro gastrointestinal digestion on the antioxidant activity of Artemisia gorgonum Webb and Hyptis pectinata (L.) Poit. infusions from Cape Verde. Food Res. Int. 2019, 115, 150-159. [CrossRef] [PubMed]

32. He, M.; Zeng, J.; Zhai, L.; Liu, Y.; Wu, H.; Zhang, R.; Li, Z.; Xia, E. Effect of in vitro simulated gastrointestinal digestion on polyphenol and polysaccharide content and their biological activities among 22 fruit juices. Food Res. Int. 2017, 102, 156-162. [CrossRef] [PubMed]

33. González-Manzano, S.; Pérez-Alonso, J.; Salinas-Moreno, Y.; Mateus, N.; Silva, A.M.S.; De Freitas, V.; Santos-Buelg, C. Flavanol-anthocyanin pigments in corn: NMR characterisation and presence in different purple corn varieties. J. Food Compos. Anal. 2008, 21, 521-526. [CrossRef]

34. Lu, L.; Song, F.-R.; Tsao, R.; Jin, Y.-R.; Liu, Z.-Q.; Liu, S.-Y. Studies on the hemolytic and heterolytic cleavage of kaempferol and kaempferide glycosides using electrospray ionization tandem mass spectrometry. Rapid Commun. Mass Spectrom. 2010, 24, 169-172. [CrossRef] [PubMed]

35. Carazzone, C.; Mascherpa, D.; Gazzani, G.; Papetti, A. Identification of phenolic constituents in red chicory salads (Cichorium intybus) by high-performance liquid chromatography with diode array detection and electrospray ionisation tandem mass spectrometry. Food Chem. 2013, 138, 1062-1071. [CrossRef] [PubMed]

36. Shi, P.; He, Q.; Song, Y.; Qu, H.; Cheng, Y. Characterization and identification of isomeric flavonoid O-diglycosides from genus Citrus in negative electrospray ionization by ion trap mass spectrometry and time-of-flight mass spectrometry. Anal. Chim. Acta 2007, 598, 110-118. [CrossRef]

37. Brito, A.; Ramirez, J.E.; Areche, C.; Sepúlveda, B.; Simirgiotis, M.J. HPLC-UV-MS profiles of phenolic compounds and antioxidant activity of fruits from three Citrus species consumed in Northern Chile. Molecules 2014, 19, 17400-17421. [CrossRef]

38. Clifford, M.N.; Johnston, K.L.; Knight, S.; Kuhnert, N. Hierarchical scheme for LC-MSn identification of chlorogenic acids. J. Agric. Food Chem. 2003, 51, 2900-2911. [CrossRef]

39. Trehan, S.; Singh, N.; Kaur, A. Characteristics of white, yellow, purple corn accessions: Phenolic profile, textural, rheological properties and muffin making potential. J. Food Sci. Technol. 2018, 55, 2334-2343. [CrossRef]

40. Gálvez Ranilla, L.; Christopher, A.; Sarkar, D.; Shetty, K.; Chirinos, R.; Campos, D. Phenolic composition and evaluation of the antimicrobial activity of free and bound phenolic fractions from a Peruvian purple corn (Zea mays L.) accession. J. Food Sci. 2017, 82, 2968-2976. [CrossRef] 
41. Milella, L.; Milazzo, S.; De Leo, M.; Vera Saltos, M.B.; Faraone, I.; Tuccinardi, T.; Lapillo, M.; De Tommasi, N.; Braca, A. $\alpha$-Glucosidase and $\alpha$-amylase Inhibitors from Arcytophyllum thymifolium. J. Nat. Prod. 2016, 79, 2104-2112. [CrossRef] [PubMed]

42. Flores, F.P.; Singh, R.K.; Kerr, W.L.; Pegg, R.B.; Kong, F. Antioxidant and enzyme inhibitory activities of blueberry anthocyanins prepared using different solvents. J. Agric. Food Chem. 2013, 61, 4441-4447. [CrossRef]

43. Di Sotto, A.; Locatelli, M.; Macone, A.; Toniolo, C.; Cesa, S.; Carradori, S.; Eufemi, M.; Mazzanti, G.; Di Giacomo, S. Hypoglycemic, antiglycation, and cytoprotective properties of a phenol-rich extract from waste peel of Punica granatum L. var. Dente di Cavallo DC2. Molecules 2019, 24, 3103. [CrossRef] [PubMed]

44. Yao, Y.; Sang, W.; Zhou, M.; Ren, G. Antioxidant and $\alpha$-glucosidase inhibitory activity of colored grains in China. J. Agric. Food Chem. 2010, 58, 770-774. [CrossRef] [PubMed]

45. Akkarachiyasit, S.; Charoenlertkul, P.; Yibchok-anun, S.; Adisakwattana, S. Inhibitory activities of cyanidin and its glycosides and synergistic effect with acarbose against intestinal $\alpha$-glucosidase and pancreatic $\alpha$-amylase. Int. J. Mol. Sci. 2010, 11, 3387-3396. [CrossRef] [PubMed]

46. Yeh, W.J.; Hsia, S.M.; Lee, W.H.; Wu, C.-H. Polyphenols with antiglycation activity and mechanisms of action: A review of recent findings. J. Food Drug Anal. 2017, 25, 84-92. [CrossRef]

47. Thilavech, T.; Abeywardenab, M.Y.; Adams, M.; Dallimore, J.; Adisakwattana, S. Naturally occurring anthocyanin cyanidin-3-rutinoside possesses inherent vasorelaxant actions and prevents methylglyoxal-induced vascular dysfunction in rat aorta and mesenteric arterial bed. Biomed. Pharmacother. 2015, 95, 1251-1259. [CrossRef]

48. Ma, H.; Johnson, S.L.; Liu, W.; DaSilva, N.A.; Meschwitz, S.; Dain, J.A.; Seeram, N.P. Evaluation of polyphenol anthocyanin-enriched extracts of blackberry, black raspberry, blueberry, cranberry, red raspberry, and strawberry for free radical scavenging, reactive carbonyl species trapping, anti-glycation, anti-amyloid aggregation, and microglial neuroprotective effects. Int. J. Mol. Sci. 2018, 19, 461. [CrossRef]

49. Suantawee, T.; Cheng, H.; Adisakwattana, S. Protective effect of cyanidin against glucose- and methylglyoxalinduced protein glycation and oxidative DNA damage. Int. J. Biol. Macromol. 2016, 93, 814-821. [CrossRef]

50. Sadowska-Barttosz, I.; Galiniak, S.; Bartosz, G. Kinetics of glycoxidation of bovin serum albumin by glucose, fructose and ribose and its prevention by food components. Molecules 2014, 19, 18828-18849. [CrossRef]

51. Justino, A.B.; Pereira, M.N.; Vilela, D.D.; Peixoto, L.G.; Martins, M.M.; Teixeira, R.R.; Miranda, N.C.; Da Silva, N.M.; De Sousa, R.M.F.; De Oliveira, A.; et al. Peel of raticum fruit (Annona crassiflora Mart.) as a source of antioxidant compounds with a-amylase, a-glucosidase and glycation inhibitory activities. Bioorg. Chem. 2016, 69, 167-182. [CrossRef]

52. Sri Harsha, P.S.C.; Gardana, C.; Simonetti, P.; Spigno, G.; Lavelli, V. Characterization of phenolics, in vitro reducing capacity and anti-glycation activity of red grape skins recovered from winemaking by-products. Biores. Technol. 2013, 140, 263-268. [CrossRef]

53. Li, Y.; Gao, F.; Gao, F.; Shan, F.; Bian, J.; Zhao, C. Study on the Interaction between 3 Flavonoid Compounds and $\alpha$-Amylase by Fluorescence Spectroscopy and Enzymatic Kinetics. J. Foos Sci. 2009, 74, 199-203. [CrossRef]

54. Rawel, H.M.; Meidtner, K.; Kroll, J. Binding of Selected Phenolic Compounds to Proteins. J. Agric. Food Chem. 2005, 53, 4228-4235. [CrossRef] [PubMed]

55. Zheng, Y.; Tian, J.; Yang, W.; Chen, S.; Liu, D.; Haitian Fang, H.; Zhang, H.; Ye, X. Inhibition mechanism of ferulic acid against $\alpha$-amylase and $\alpha$-glucosidase. Food Chem. 2020, 317, 126346. [CrossRef] [PubMed]

56. Xiao, J.; Kai, G.; Ni, X.; Yang, F.; Chen, X. Interaction of natural polyphenols with a-amylase in vitro: Molecularproperty-affinity relationship aspect. Mol. BioSyst. 2011, 7, 1883-1890. [CrossRef] [PubMed]

57. Pinto, J.; Spínola, V.; Llorent-Martínez, E.J.; Fernández-de Córdova, M.L.; Molina-García, L.; Castilho, P.C. Polyphenolic profile and antioxidant activities of Madeiran elderberry (Sambucus lanceolata) as affected by simulated in vitro digestion. Food Res. Int. 2017, 100, 404-410. [CrossRef]

58. Gullon, B.; Pintado, M.E.; Fernández-López, J.; Pérez-Álvarez, J.A.; Viuda-Martos, M. In vitro gastrointestinal digestion of pomegranate peel (Punica granatum) flour obtained from co-products: Changes in the antioxidant potential and bioactive compounds stability. J. Food Funct. 2015, 19, 617-628. [CrossRef]

59. Gardeli, C.; Varela, K.; Krokida, E.; Mallouchos, A. Investigation of anthocyanins stability from pomegranate juice (Punica granatum L. cv Ermioni) under a simulated digestion process. Medicines 2019, 6, 90. [CrossRef] 
60. Chiang, Y.C.; Chen, C.L.; Jeng, T.L.; Linc, T.C.; Sung, J.M. Bioavailability of cranberry bean hydroalcoholic extract and its inhibitory effect against starch hydrolysis following in vitro gastrointestinal digestion. Food Res. Int. 2014, 64, 939-945. [CrossRef]

61. Tavares, L.; Figueira, I.; Macedo, D.; McDougall, G.J.; LeitãO, M.C.; Vieira, H.L.A.; Stewart, D.; Alves, P.M.; Ferreira, R.B.; Santos, C.N. Neuroprotective effect of blackberry (Rubus sp.) polyphenols is potentiated after simulated gastrointestinal digestion. Food Chem. 2012, 131, 1443-1452. [CrossRef]

62. Scorrano, S.; Lazzoi, M.R.; Mergola, L.; Di Bello, M.P.; Del Sole, R.; Vasapollo, G. Anthocyanins profile by Q-TOF LC/MS in Myrtus communis berries from Salento Area. Food Anal. Met. 2017, 10, 2404-2411. [CrossRef]

63. Maietta, M.; Colombo, R.; Corana, F.; Papetti, A. Cretan tea (Origanum dictamnus L.) as a functional beverage: An investigation on antiglycative and carbonyl trapping activities. Food Funct. 2017, 9, 1545-1556. [CrossRef] [PubMed]

64. Sompong, W.; Meeprom, A.; Cheng, H.; Adisakwattana, S. A comparative study of ferulic acid on different monosaccharide-mediated protein glycation and oxidative damage in bovine serum albumin. Molecules 2013, 18, 13886-13903. [CrossRef]

65. Minekus, M.; Alminger, M.; Alvito, P.; Ballance, S.; Bohn, T.; Bourlieu, C.; Carrière, F.; Boutrou, R.; Corredig, M.; Dupont, D.; et al. A standardised static in vitro digestion method suitable for food-an international consensus. Food Funct. 2014, 5, 1113-1124. [CrossRef]

66. Hamzalığlu, A.; Gökmen, V. Investigations on the reactions of $\alpha$-dicarbonyl compounds with amino acids and proteins during in vitro digestion of biscuits. Food Funct. 2016, 7, 2544-2550. [CrossRef]

Sample Availability: Samples of the compounds are not available from the authors.

(C) 2020 by the authors. Licensee MDPI, Basel, Switzerland. This article is an open access article distributed under the terms and conditions of the Creative Commons Attribution (CC BY) license (http://creativecommons.org/licenses/by/4.0/). 